\title{
Current Advances of Nanocarrier Technology-Based Active Cosmetic Ingredients for Beauty Applications
}

\author{
Hong Zhou' \\ Dan Luo ${ }^{2}$ \\ Dan Chen ${ }^{2}$ \\ Xi Tan' \\ Xichen Bai' \\ Zhi Liu' \\ Xiangliang Yang ${ }^{1,2}$ \\ Wei Liu ${ }^{1,2}$ \\ 'College of Life Science and Technology, \\ Huazhong University of Science and \\ Technology, Wuhan, 430074, Hubei, \\ People's Republic of China; ${ }^{2}$ National \\ Engineering Research Center for \\ Nanomedicine, Huazhong University of \\ Science and Technology, Wuhan, 430075, \\ Hubei, People's Republic of China
}

\begin{abstract}
Nanocarrier technology has been effectively applied to the development of drug delivery systems to overcome the limitations of traditional preparation. Its application has been extended to various pharmaceutical fields from injection preparation to oral preparation and external preparation, and now it has appeared in the field of cosmetics for beauty applications. The widespread influence of nanocarrier in the cosmetics industry is due to the fact that nanocarrier can effectively promote the percutaneous penetration and significantly increase skin retention of active components in functional cosmetics. Meanwhile, nanocarrier can effectively improve the water dispersion of insoluble active cosmetic ingredients, enhance the stability of efficacy components and achieve the codelivery of diverse cosmetics active ingredients. In this review, we summarized the current progress of nanocarrier technology in the functional cosmetics, including the types and the routes of dermal/ transdermal drug delivery nanocarriers used in the functional cosmetics, the mechanism of nanocarriers promoting the percutaneous penetration of active cosmetic ingredients, the application and efficacy evaluation of different active cosmetic ingredients in nanocarriers and discussing the potential risks to human. This will provide a useful reference for the further development of nanocarriers in the field of functional cosmetics.
\end{abstract}

Keywords: nanocarrier technology, functional cosmetics, active cosmetic ingredients, skin penetration and positioning, efficacy evaluation, codelivery nanocarriers

\section{Introduction}

Nanocarriers, also known as nanocarrier drug-delivery systems, refer to a new class of pharmaceutical preparations developed by using nanometer preparation technology, which is the core technology of nanometer drugs. As one of the most industrialized and promising technologies in nanotechnology, the research and development of nanocarriers have become the current international frontier and hot spot. Recent studies have demonstrated that nanocarriers can effectively promote the penetration of cosmetic efficacy components through the stratum corneum and significantly increase the skin retention of efficacy components. ${ }^{1}$ Meanwhile, nanocarriers can effectively improve the water dispersion of insoluble active ingredients and potentiate the stability of active ingredients. ${ }^{2}$ These show a good application prospect in the solution of skin problems, treatment of skin diseases and skin care and beauty.

Since 1986, Christian Dior launched the first cosmetics (Capture) applied by liposome technology, ${ }^{3}$ and then the research of nanocarrier technology in functional
Correspondence: Wei Liu College of Life Science and Technology, Huazhong University of Science and Technology, 1037 Luoyu Road, Wuhan, 430075, Hubei, People's Republic of China $\mathrm{Tel} / \mathrm{Fax}+862787792147$

Email wliu@hust.edu.cn 
cosmetics has been promptly developed. Functional cosmetics products using nanocarrier technology have been listed successively (Table 1), showing the broad application prospect of nanocarrier technology in the field of cosmetics. $^{4-6}$ Studies have revealed that the application of nanocarrier technology in functional cosmetics can realize the skin targeted transportation of efficacy components, enable the efficacy components to enter target sites and target cells, and achieve the functions of sustained release, controlled release, long-term release and so on. ${ }^{5}$ At the same time, it can effectively augment the stability of light/heat sensitive components and improve the compatibility of efficacy components. ${ }^{1}$

In recent years, cosmetics containing natural plant active ingredients have been favored by consumers. The application of plant active ingredients in functional cosmetics often has several problems such as poor solubility and stability, low skin permeability and skin irritation, which limit the application of plant active ingredients in functional cosmetics. ${ }^{7}$ Nanocarrier technology solves the above problems well and greatly expands the application of plant active ingredients in functional cosmetics (Table 2) ${ }^{8,9}$ In addition, skin care often needs to consider multifaceted factors, ${ }^{10,11}$ which lead to the need for synergistic effects of multiple efficacy components in functional cosmetics. However, at present, the active ingredients of most functional cosmetic products on the market are single, or the physicochemical properties of different efficacy ingredients are greatly different, resulting in poor compatibility and difficulty in transdermal absorption. The specially designed nanocarriers can simultaneously load multifarious efficacy components with different physical and chemical properties. By transdermal co-delivery of skincare efficacy components, the synergistic effect of multi-effect and multi-target skincare efficacy components can be realized. ${ }^{12}$

In this Review, we summarize the research progress of nanocarrier technology in functional cosmetics, including the types and the routes of dermal/transdermal drug delivery nanocarriers used in functional cosmetics, the mechanism by which nanocarriers promote the transdermal penetration of active cosmetic ingredients, the application and efficacy evaluation of different active cosmetic ingredients in nanocarriers and discussing the potential risks to human, which will provide reference for the further development of nanocarriers in the field of functional cosmetics.

\section{The Types and the Routes of Dermal/Transdermal Drug Delivery Nanocarriers \\ The Types of Dermal/Transdermal Drug Delivery Nanocarriers in Cosmetics}

The types of dermal/transdermal drug delivery nanocarriers used in cosmetics include microemulsions/nanoemulsions, liposomes, lipid nanoparticles, lipid liquid crystals, nanocrystals, polymer nanocarriers and inorganic nanocarriers. The particle size is the primary characteristic of nanocarriers, which constitutes an important material basis for the special biological effects of nanocarriers. Compared with the size of nanomaterials defined in the field of materials science $(0.1 \sim$ $100 \mathrm{~nm}$ ), extensive research has indicated that when the particle size of the nanocarrier is from 10 to $1000 \mathrm{~nm}$, the efficacy components are distinctly different from the traditional preparations in terms of physical and chemical properties, pharmacokinetics and pharmacodynamics. ${ }^{13}$ When cosmetic efficacy components are loaded into nanocarriers in different ways including dissolution, dispersion, encapsulation, adsorption and coupling, its physical and chemical properties (such as saturated solubility, dissolution rate, crystal type, hydrophilic and hydrophobic, and stability) and biological characteristics (such as specific molecular affinity, cell affinity and biodegradability) are altered, thus affecting the absorption, distribution, metabolism and excretion of efficacy components (such as changing skin transdermal permeation, biological adhesive, internal stability and targeting property, slow/controlled release characteristics and cellular uptake). In this way, the bioavailability and therapeutic effect of cosmetic efficacy components can be heightened and its adverse reactions can be attenuated.

\section{The Routes of Dermal/Transdermal Drug Delivery Nanocarriers}

Based on the existing literature, ${ }^{14}$ there are three main routes by which nanocarriers can promote percutaneous absorption of efficacy components (Figure 1): (1) The nanocarriers penetrate by skin appendages including hair follicles and sebaceous glands and deliver cosmetic efficacy components to surrounding tissues, (2) Interactions between nanocarriers and the skin stratum corneum can enhance permeability of efficacy components, (3) The deformable nanocarriers in intact form penetrate the living cell layer of the skin by the intercellular route of stratum corneum. 
Table I List of Nanocarriers Applied in Functional Cosmetic Products

\begin{tabular}{|c|c|c|c|}
\hline Nanocarriers & Product & Proposed Use & Manufacturer \\
\hline Nanoemulsions & $\begin{array}{l}\text { Vitacos Vita-Herb Nona-Vital Skin Toner } \\
\text { Precision-Solution Destressante Solution Nano Emulsion } \\
\text { Peaux Sensitivity } \\
\text { Coni Hyaluronic Acid \& Nanoemulsion Intensive } \\
\text { Hydration Toner } \\
\text { Phyto-Endorphin Hand Cream } \\
\text { Bepanthol-Protect Facial Cream Ultra }\end{array}$ & $\begin{array}{l}\text { Moisturizer } \\
\text { Moisturizer } \\
\text { Moisturizer } \\
\text { Anti-aging } \\
\text { Moisturizer/Anti-aging }\end{array}$ & $\begin{array}{l}\text { Vitacos Cosmetics } \\
\text { Chanel } \\
\text { Coni Beauty } \\
\text { Rhonda Allison } \\
\text { Bayer HealthCare }\end{array}$ \\
\hline Liposomes & $\begin{array}{l}\text { Azelac Ru Serum } \\
\text { Seskavel Mulberry Anti-Hair Loss Foam } \\
\text { C-Vit Facial Serum } \\
\text { Daeses Lifting Cream } \\
\text { Acglicolic Classic Crema Hidratante SPF I5 } \\
\text { Isocell }^{\text {TM }} \text { MAP } \\
\text { Capture } \\
\text { Eye Defense Cream } \\
\text { Derma Stemness Reviving Serum } \\
\text { Royal Jelly Lift Concentrate } \\
\text { Decorte Moisture Liposome Face Cream } \\
\text { Dermosome } \\
\text { Kerstin Florian Rehydrating Liposome Day Creme } \\
\text { Premier Bio Performance Liposome } \\
\text { Moisture Liposome Cream } \\
\text { Clinicians Complex Liposome Face \& Neck Lotion } \\
\text { Russell Organics Liposome Concentrate } \\
\text { Lumessence Eye Cream }\end{array}$ & $\begin{array}{l}\text { Whitening } \\
\text { Anti-alopecia } \\
\text { Anti-aging } \\
\text { Anti-aging } \\
\text { Anti-aging } \\
\text { Anti-aging } \\
\text { Anti-wrinkle } \\
\text { Anti-wrinkle } \\
\text { Anti-wrinkle } \\
\text { Anti-wrinkle } \\
\text { Moisturizer } \\
\text { Moisturizer } \\
\text { Moisturizer } \\
\text { Moisturizer } \\
\text { Moisturizer } \\
\text { Moisturizer/Anti-aging } \\
\text { Moisturizer/Anti-aging } \\
\text { Anti-wrinkle/Anti-aging }\end{array}$ & $\begin{array}{l}\text { Sesderma } \\
\text { Sesderma } \\
\text { Sesderma } \\
\text { Sesderma } \\
\text { Sesderma } \\
\text { Lucas Meyer Cosmetic } \\
\text { Christian Dior } \\
\text { L'Oreal Paris } \\
\text { Kaya skin clinic } \\
\text { Royal Jelly } \\
\text { Decorte } \\
\text { Microfuidics } \\
\text { Kerstin Florian } \\
\text { Dead Sea Premier } \\
\text { Cosme decorte } \\
\text { Clinicians Complex } \\
\text { Russell Organics } \\
\text { Aubrey Organics }\end{array}$ \\
\hline $\begin{array}{l}\text { Solid lipid } \\
\text { nanoparticles }\end{array}$ & $\begin{array}{l}\text { Allure Body Cream } \\
\text { Soosion Facial Lifing Cream SLN Technology } \\
\text { Phyto NLC Active Cell Repair }\end{array}$ & $\begin{array}{l}\text { Moisturizer } \\
\text { Anti-wrinkle } \\
\text { Moisturizer/Whitening }\end{array}$ & $\begin{array}{l}\text { Chanel } \\
\text { Soosion } \\
\text { Sireh Emas }\end{array}$ \\
\hline $\begin{array}{l}\text { Nanostructured lipid } \\
\text { carriers }\end{array}$ & $\begin{array}{l}\text { Swiss Cellular White Illuminating Eye Essence } \\
\text { Surmer Creme Leg ere Nano-Protection } \\
\text { lope Supervital Extra Moist Sofner } \\
\text { Olivenol Anti Falten Pfegekontrat } \\
\text { Surmer Masque Creme Nano-Hydratant } \\
\text { Regenerations Cream Intesive Ampoules } \\
\text { Cutanova-Cream Nanorepair Q10 }\end{array}$ & $\begin{array}{l}\text { Whitening } \\
\text { Moisturizer } \\
\text { Moisturizer } \\
\text { Anti-wrinkle } \\
\text { Moisturizer/Anti-wrinkle } \\
\text { Anti-wrinkle/Anti-aging } \\
\text { Anti-wrinkle/Anti-aging }\end{array}$ & $\begin{array}{l}\text { La prairie } \\
\text { Isabelle Lancray } \\
\text { Amore Pacifc } \\
\text { Dr. Teiss/Medipharma } \\
\text { cosmetics } \\
\text { Isabelle Lancray } \\
\text { Scholl } \\
\text { Dr. Rimpler }\end{array}$ \\
\hline Niosomes & $\begin{array}{l}\text { Niosome Plus } \\
\text { Niosome+ Perfected Age Treatment } \\
\text { Anti-Age Response Cream } \\
\text { Niosome+ } \\
\text { Guinot deep action lightening serum } \\
\text { Eusu Niosome Makam Pom Whitening Facial Cream } \\
\text { Identik Masque Floral Repair } \\
\text { Identik Shampooing Floral Repair } \\
\text { Mayu Niosome Base Cream }\end{array}$ & $\begin{array}{l}\text { Anti-aging } \\
\text { Anti-wrinkle } \\
\text { Anti-wrinkle } \\
\text { Whitening } \\
\text { Whitening } \\
\text { Whitening } \\
\text { Anti-alopecia } \\
\text { Anti-alopecia } \\
\text { Moisturizer/Whitening }\end{array}$ & $\begin{array}{l}\text { Lancome } \\
\text { Lancome } \\
\text { Simply Man Match } \\
\text { Lancome } \\
\text { Guinot } \\
\text { Eusu } \\
\text { Identik } \\
\text { Identik } \\
\text { Laon Cosmetics }\end{array}$ \\
\hline
\end{tabular}

(Continued) 
Table I (Continued).

\begin{tabular}{|c|c|c|c|}
\hline Nanocarriers & Product & Proposed Use & Manufacturer \\
\hline Nanocapsules & $\begin{array}{l}\text { Hydra Flash Bronzer Daily Face moisturizer } \\
\text { Hydra Zen Cream } \\
\text { Primordiale Optimum Lip } \\
\text { Soleil Instant Cooling Sun Spritz SPF I5 } \\
\text { Soleil Sof-Touch Anti-Wrinkle Sun Cream SPF I5 } \\
\text { Eye Contour Nanolif }\end{array}$ & $\begin{array}{l}\text { Moisturizer } \\
\text { Moisturizer } \\
\text { Lip treatment } \\
\text { Sunscreen } \\
\text { Anti-wrinkle/Sunscreen } \\
\text { Anti-wrinkle/Anti-aging }\end{array}$ & $\begin{array}{l}\text { Lancome } \\
\text { Lancome } \\
\text { Lancome } \\
\text { Lancome } \\
\text { Lancome } \\
\text { Euoko }\end{array}$ \\
\hline Nanospheres & $\begin{array}{l}\text { Clearly It! Complexion Mist } \\
\text { Fresh As A Daisy Body Lotion } \\
\text { Cell Act DNA Filler Intense Cream } \\
\text { Nano Saltmmoisture Key } \\
\text { Coryse Salome Competence Hydration Ultra-Moisturizing } \\
\text { Cream } \\
\text { Hydralane Ultra Moisturizing Day Cream } \\
\text { Nanosphere Plus }\end{array}$ & $\begin{array}{l}\text { Anti-acne } \\
\text { Anti-wrinkle } \\
\text { Anti-wrinkle } \\
\text { Moisturizer } \\
\text { Moisturizer } \\
\text { Moisturizer } \\
\text { Anti-aging/Anti-wrinkle }\end{array}$ & $\begin{array}{l}\text { Kara Vita } \\
\text { Kara Vita } \\
\text { CellAct Switzerland } \\
\text { Salvona } \\
\text { Coryse Salome Paris } \\
\text { Hydralane Paris } \\
\text { DermaSwiss }\end{array}$ \\
\hline Gold nanoparticles & $\begin{array}{l}\text { Nano Gold Firming Treatment } \\
\text { Chantecaille Nano Gold Energizing Cream } \\
\text { LR Nano Gold Day \& Silk Day Cream } \\
\text { Nuvoderm Nano Gold Anti-Aging Lifing Serum } \\
\text { Orogold } 24 \mathrm{~K} \text { Nano Ultra Silk Serum } \\
\text { Ameizii Nano Gold Foil Liquid } \\
\text { Tony Moly Nano Gold BB Cream SPF } 50 \text { PA+++ } \\
\mathrm{O}^{3+} 24 \mathrm{~K} \text { Gold Gel Cream }\end{array}$ & $\begin{array}{l}\text { Anti-aging } \\
\text { Anti-aging } \\
\text { Anti-aging } \\
\text { Anti-aging/Anti-wrinkle } \\
\text { Anti-aging/Anti-wrinkle/ } \\
\text { Moisturizer } \\
\text { Anti-aging/Whitening/ } \\
\text { Moisturizer } \\
\text { Whitening/Anti-wrinkle/ } \\
\text { Sunscreen } \\
\text { Whitening/Anti-wrinkle/ } \\
\text { Sunscreen }\end{array}$ & $\begin{array}{l}\text { Chantecaille } \\
\text { Chantecaille } \\
\text { LR Zeitgard } \\
\text { Nuvoderm } \\
\text { Orogold } \\
\text { Ameizii } \\
\text { Tony Moly } \\
\mathrm{O}^{3+}\end{array}$ \\
\hline Silver nanoparticles & $\begin{array}{l}\text { Cosil Whitening Mask } \\
\text { Lancome Renergie Microlif } \\
\text { Nano Cyclic Cleanser Silver }\end{array}$ & $\begin{array}{l}\text { Whitening } \\
\text { Anti-wrinkle } \\
\text { Anti-wrinkle/Anti-acne/ } \\
\text { Freckle-removing }\end{array}$ & $\begin{array}{l}\text { Natural Korea } \\
\text { Lancome } \\
\text { Nano Cyclic }\end{array}$ \\
\hline Fullerene $\mathrm{C}_{-60}$ & Zelens Fullerene $\mathrm{C}_{-60}$ Night Cream & Anti-aging & Zelens \\
\hline
\end{tabular}

\section{The Permeation of Nanocarriers via Skin} Appendages

Nanocarriers can penetrate through skin appendages including hair follicles, sebaceous glands and sweat glands, which were collectively termed the transappendageal route. Nanocarriers accumulating the deep of the hair follicle generate a depot effect and slowly release the efficacy components. Hair follicles extend up to $1000 \mu \mathrm{m}$ deep into the dermis and form a three-dimensional contact surface with the skin, which provide sufficient absorption area for the efficacy components. ${ }^{15}$ Studies have shown that the permeability behavior of hair follicles of nanocarriers is closely related to their particle sizes. Lipid-based nanocarriers of less or equal to $640 \mathrm{~nm}$ can penetrate into hair follicles. ${ }^{16}$ Smaller particle size nanocarriers can penetrate into the bottom of hair follicles and show more accumulation and stronger permeability. The observations uncover that $40 \mathrm{~nm}$ polymeric nanoparticles may enter the perifollicular dermis, ${ }^{17}$ whereas polymeric nanoparticles of $300 \mathrm{~nm}$ penetrate up to $300 \mu \mathrm{m}$ deep into the hair follicles. ${ }^{18}$ In addition, microparticles with a size of 3-10 $\mu \mathrm{m}$ may reach the orifices of hair follicles or even block them. ${ }^{16}$

\section{Interactions Between Nanocarriers and the Skin Stratum Corneum}

The skin stratum corneum-nanocarriers interactions, known as intracellular route, include increased stratum 


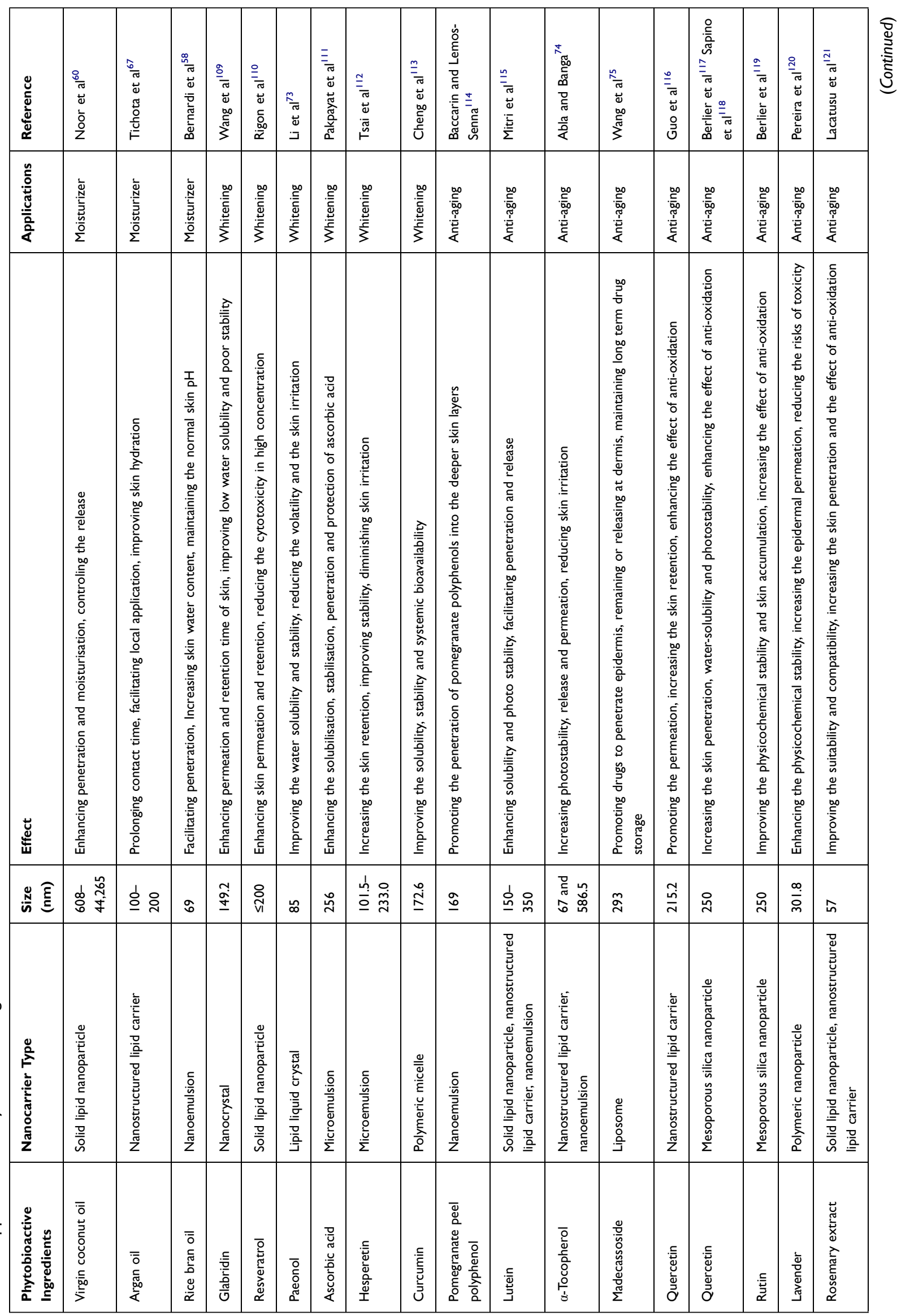




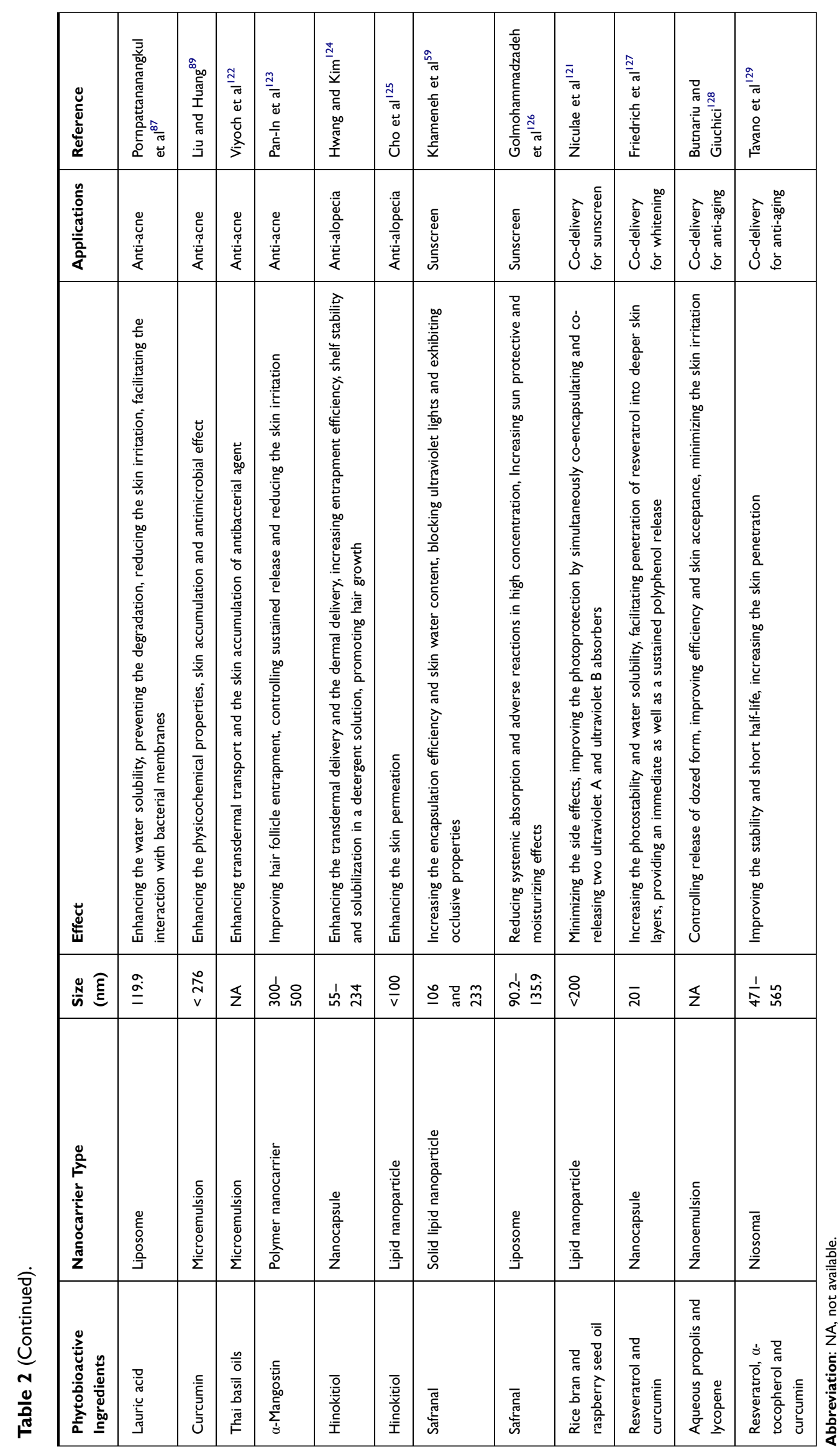




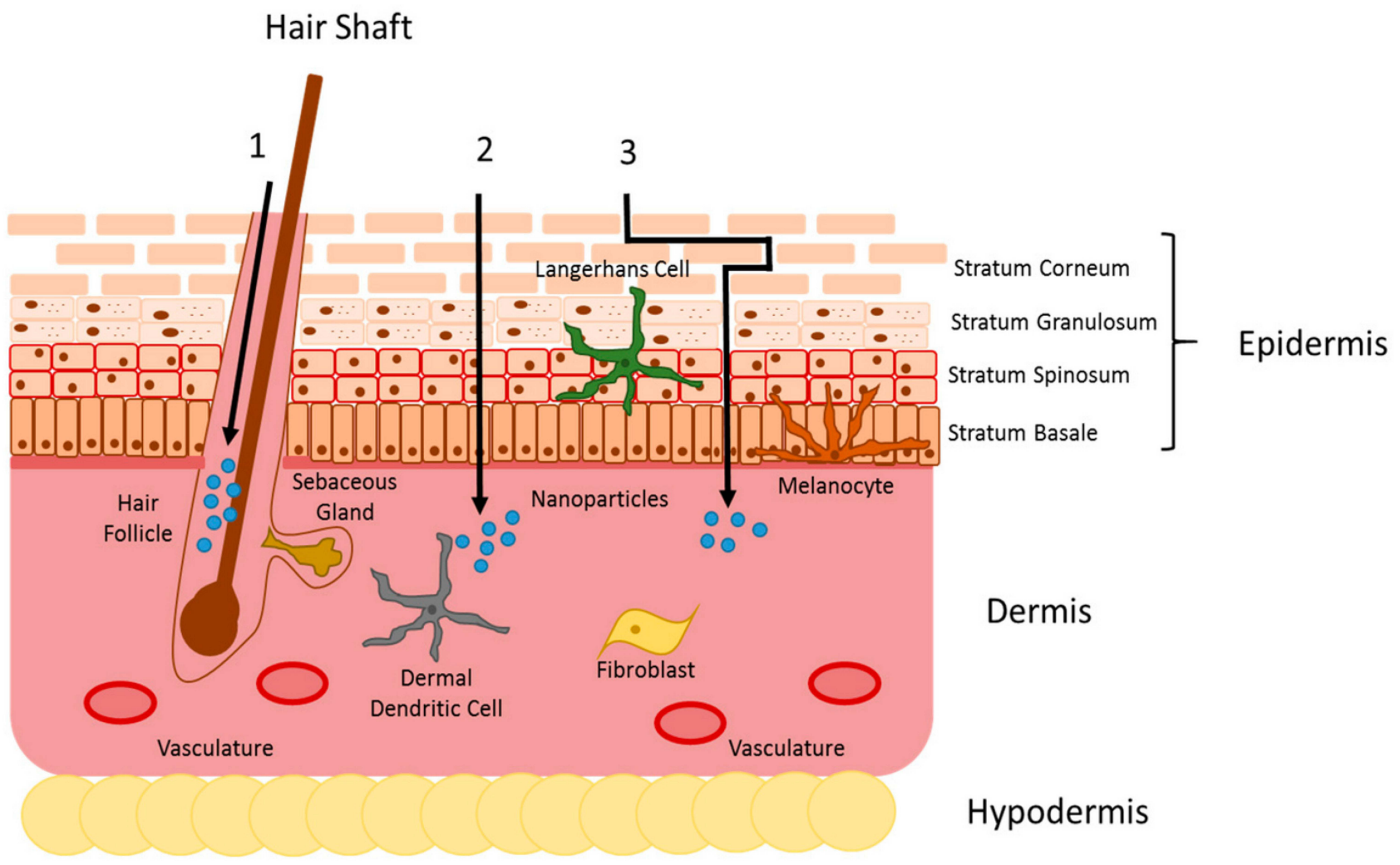

Figure I Mechanisms of nanocarriers promoting percutaneous absorption of efficacy components.

Notes: Reprinted from Palmer BC, DeLouise LA. Nanoparticle-enabled transdermal drug delivery systems for enhanced dose control and tissue targeting. Molecules. 2016;2I(I2):7-9. ${ }^{14}$ Creative Commons CC-BY 4.0 (https://creativecommons.org/licenses/by/4.0/legalcode).

corneum hydration by sticking to the skin surface, lipid exchange occurring between nanocarriers and stratum corneum, and enhanced fluidity and improved polarity of lipid bilayer of stratum corneum. The interactions can disorganize the lipid structure of stratum corneum by changing its composition of the stratum corneum lipid and tight arrangement of the bilayer, and weaken the barrier effect of the stratum corneum to increase drug penetration by increasing the mobility and permeability of lipids in the skin. Noteworthy, the effect of nanocarriers on the lipid bilayer of stratum corneum is mild and reversible, without permanent damage to its structure. However, due to the low permeability of the stratum corneum cells and the multiple hydrophilic/lipophilic distribution of drugs through the intracellular route, the intracellular route is only a minimal part of the transdermal drug delivery of nanocarriers.

\section{Nanocarriers Crossing the Intercellular Gap of Stratum Corneum}

The intact nanocarriers cross the stratum corneum by the intercellular gap, which is the main route for nanocarriers to carry the efficacy components into the active epidermis and dermis, and then to be absorbed into the systemic circulation. The composition, structure, particle size and surface charge of the nanocarriers affect its penetration behavior and penetration depth in the skin. Solid lipid nanoparticles and nanostructured lipid carriers are mainly retained in the stratum corneum due to their strong lipophilic properties. Due to the poor membrane fluidity and elasticity, it is difficult for the conventional liposomes to cross the stratum corneum in an intact form. Considering that the modified liposomes (such as transporters, alcohols and terpene liposomes) have better deformation capacity, and modifiers (such as cholate, ethanol and terpene) have stronger disturbance to the arrangement structure of cuticle, the research have shown that such nanocarriers with suitable particle sizes can penetrate the complete skin. ${ }^{19}$ Moreover, low generation dendrimers can penetrate into the stratum corneum in intact form, but the extent and route of their penetration are influenced by its surface properties including polarity and electric charge. ${ }^{20}$ Furthermore, the intact inorganic nanocarriers such as mesoporous silicon nanoparticles, gold nanoparticles and 


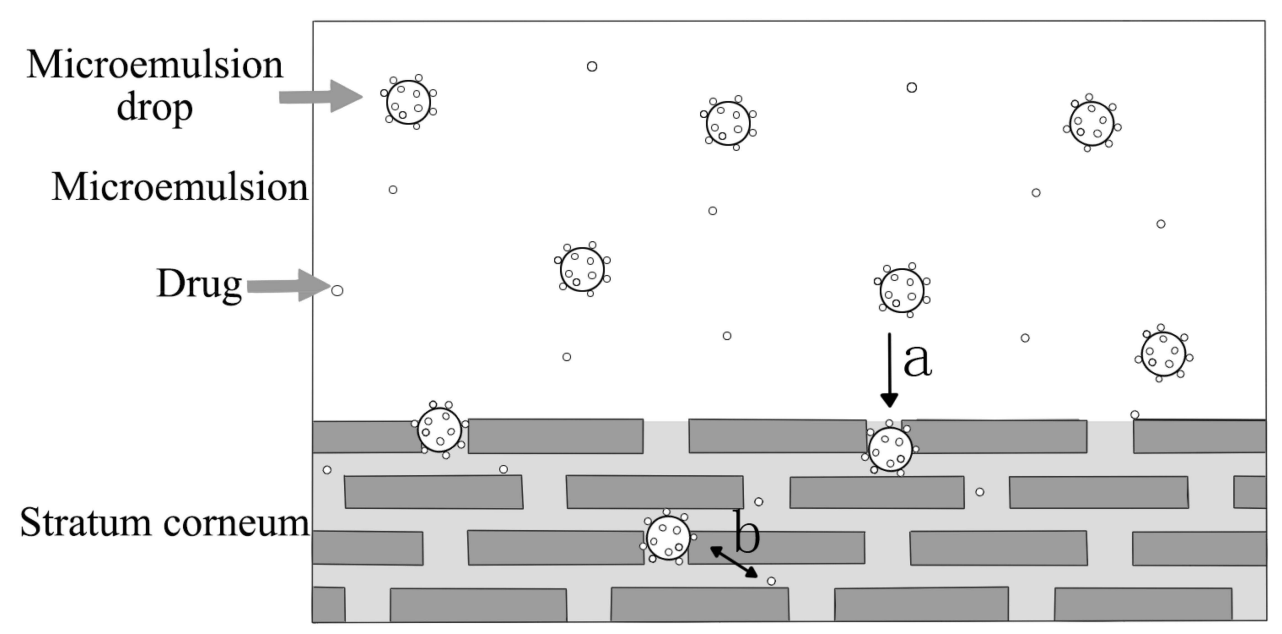

Figure 2 Schematic of the mechanism of microemulsion-mediated intercellular infiltration in the stratum corneum. In step (a) the microemulsion drop loading the drug penetrates through the porous structure of the skin. In step (b) the drug is released from the microemulsion droplet into the surrounding cell space.

quantum dots with suitable particle size and surface modification can also pass the stratum corneum.

\section{Mechanism of Nanocarriers Promoting Dermal/Transdermal Delivery of Active Cosmetic Ingredients}

Skin penetration and positioning of efficacy components are important conditions for functional cosmetics to play their role in protecting skin. However, it is still difficult to accurately evaluate the behavior of nanocarriers in the skin and the exact process of promoting the penetration of efficacy components through the skin barrier. Therefore, the elucidation of the promoting permeability mechanism of nanocarriers provides theoretical support for the design of ideal nanocarriers of functional cosmetic and the effective improvement of skin efficacy components' percutaneous permeability efficiency.

\section{Microemulsions/Nanoemulsions}

Microemulsions are a thermodynamically stable isotropic dispersive system formed spontaneously by oil, water and surfactant. Nanoemulsions are considered as a kind of conventional emulsion containing very small droplets and is a thermodynamically unstable colloidal dispersion system. ${ }^{21}$ The surfactant interface between the oil phase and the water phase of the microemulsions and nanoemulsions creates additional solubility region, which improves the drug loading capacity of the emulsion. ${ }^{22}$ For example, incorporation of resveratrol into microemulsions resulted in improved solubility (over 23-fold) compared to crystalline resveratrol. ${ }^{23}$ The percutaneous absorption route of most drugs in microemulsion and nanoemulsion is through the intercellular gap. For instance, microemulsions mediated intercellular infiltration in the stratum corneum (Figure 2). ${ }^{24}$ The microemulsions loading the drug enter the intercellular gap from the skin surface (Step a) and then release the drug into the surrounding cell space (Step b), allowing the drug to penetrate into the deeper tissues of the skin. In the process of transdermal absorption, the water in microemulsions is rapidly absorbed into the skin to form supersaturated solution, which increases the drug diffusion pressure and thus significantly potentiates the rate of transdermal absorption. ${ }^{25}$

In additional, there are also small amounts of free drug uptake via intracellular route. ${ }^{26}$ The surfactants, cosurfactants and oil phases used in the preparation of microemulsions and nanoemulsions usually have a certain permeability promoting effect, which can reverse and temporarily destroy the double layer structure of the lipid in the stratum corneum, increase the fluidity of the lipid in the stratum corneum, and thus fortify the transdermal permeability of drugs. Meanwhile, surfactants, cosurfactants and oil phases, as permeability enhancers, can perform a "diffuse-distribution-dissolution" effect in the skin, thereby elevating the percutaneous absorption of drugs. ${ }^{27}$ Furthermore, skin hair follicles are closely related to drug percutaneous penetration, which is an important storage of drugs in the skin and also a channel for particles to percutaneous penetration. ${ }^{28}$ The $\mathrm{W} / \mathrm{O}$ nanoemulsion is compatible with the lipophile sebaceous environment of hair follicles and promotes the effective transport of the hydrophilic drug in the skin. ${ }^{29}$ 


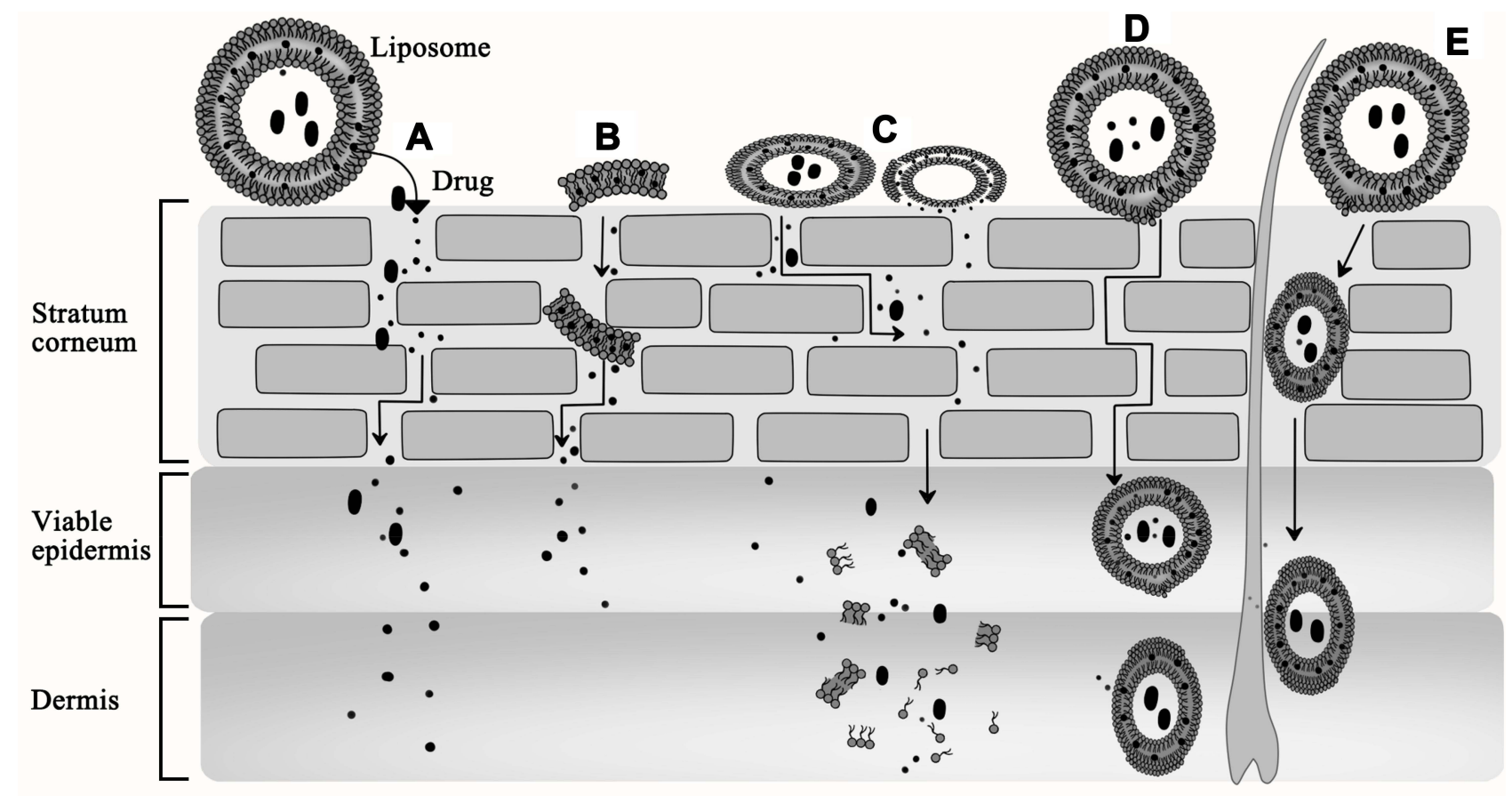

Figure 3 Different mechanisms of percutaneous infiltration of liposomes. (A) Liposomes release drugs outside the stratum corneum by the hydration; (B) Lipid flakes after rupture of liposomes play a role in promoting permeability; (C) Liposomes fuse with the stratum corneum; (D) Some deformable liposomes pass through the stratum corneum in their intact form; (E) Liposomes enter the skin via hair follicles and/or sebaceous glands.

As dermal/transdermal drug delivery nanocarriers, microemulsions and nanoemulsions are characterized by strong skin permeability, large load, good wettability, spreading and stability on the skin surface. Therefore, the colloid delivery system based on microemulsions or nanoemulsions is applied more and more widely in the field of cosmetics. 22,30

\section{Liposomes}

Liposomes, also known as lipid vesicles, are similar to the stratum corneum in structure and composition and can deliver the efficacy ingredients to the target site of the skin through fusion (Figure 3C). Lipid exchange resulting from this fusion can also form lipid flakes in the intercellular gap of stratum corneum, loosening the cuticle and facilitating drug penetration (Figure $3 \mathrm{~B}$ ). ${ }^{31}$ By significantly improving the hydration of the skin stratum corneum, liposomes can change the arrangement and structure of the hydrophobic part in the lipid bilayer of the stratum corneum so that drugs can easily penetrate the stratum corneum (Figure 3A). Lipid composition contained in liposomes also forms a lipid film on the skin surface, which can decrease skin moisture loss, improve the water content of the stratum corneum, and promote drug penetration.
Of note, the improved liposomes such as transfersomes, ethosomes, niosomes and so on have deformable ability, which enables them to penetrate the stratum corneum by the intercellular gap and deliveries drugs into the deep tissues of the skin (Figure 3D). ${ }^{32,33}$ For example, transfersomes can cross the intercellular space of the stratum corneum by deformable ability and widen the space between keratinocytes to promote the percutaneous penetration of efficacy components by osmotic pressure. ${ }^{34}$ By changing the lipid structure of the stratum corneum, ethosomes can accumulate in the deep layer of the skin to significantly enhance the penetration depth and skin retention of efficacy components. ${ }^{35}$ Besides, ethanol contained in the ethosomes is a skin penetration enhancer that enhances percutaneous penetration by affecting the physicochemical properties of the ethosomes (such as particle size, zeta potential, membrane fluidity and solubility). Niosomes promote transdermal absorption of efficacy components and increase its retention in the stratum corneum and active epidermis to prolongate action time by reducing skin tension.

Nanoparticles with wettability on the surface have a good affinity with hair follicle tissue, and are easier to be absorbed by hair follicles than nanoparticles with hydrophobic surface. Liposomes just have this advantage. 
Topical delivery of liposomes encapsulated gamma-interferon into hairless mouse, human and hamster skin showed that the hamster skin with the densest distribution of hair follicles had the highest cumulative skin retention. ${ }^{36}$ The hair follicle uptake rate of PLGA nanoparticles coated with liposomes as drug carriers was $6.95 \pm 2.30 \%$, which was significantly higher than that of PLGA nanoparticles coated without liposomes $(3.15 \pm 1.23 \%){ }^{37}$ These results hint that transappendageal route is an important pathway for liposomes to promote drug transdermal absorption (Figure 3E).

\section{Lipid Nanoparticles}

Lipid nanoparticles, composed of solid lipid nanoparticles and nanostructured lipid carriers, are colloidal dispersion systems prepared by solid lipids or mixtures of solid lipids and lipid liquid. As the first generation of lipid nanoparticles, solid lipid nanoparticles combine the advantages of nanoparticles and liposomes. With the evaporation of water from the solid lipid nanoparticles used to the skin surface, solid lipid nanoparticles form an adhesive layer occluding the surface of skin. ${ }^{38}$ Then increased hydration of the stratum corneum can diminish corneocyte packing and widen the intercellular gap of stratum corneum, which fosters efficacy components penetration into deeper skin layer. $^{39,40}$ The smaller the size of solid lipid nanoparticles is, the stronger the hydration is and the stronger the interference effect on the lipid arrangement of skin is. ${ }^{41}$ In addition, solid lipid nanoparticles can be inserted into the lipid region of the skin stratum corneum, which destroys its bilayer structure and causes lipid rearrangement, thereby reducing the resistance of drug molecules to penetrate the skin stratum corneum. Furthermore, efficacy components dissolved in the lipid region of the solid lipid nanoparticles can be distributed directly to the lipids in the stratum corneum of skin in a high concentration gradient. These interactions between solid lipid nanoparticles with the skin stratum corneum not only promote efficacy components penetration through the stratum corneum but also enhance their passive diffusion in the skin. Noteworthy, due to their high lipophilicity, solid lipid nanoparticles can reach deep areas of the skin via transappendageal route where sebaceous glands secrete a large amount of oils, mainly short-chain fatty acids. ${ }^{42}$

Nanostructured lipid carriers are a new generation of lipid nanoparticles developed on the basis of solid lipid nanoparticles. By adding liquid lipids, nanostructured lipid carriers disturb the crystal lattice formation of solid lipids, thus notably elevating the drug loading and stability. Owing to the improvement of drug loading and stability, nanostructured lipid carriers are not only applied in the field of transdermal drug delivery but also shows good potential application in the field of efficacy cosmetics. ${ }^{43}$

\section{Lipid Liquid Crystals}

Lipid liquid crystals can enhance the stability of the emulsion and be loaded with both hydrophilic and lipophilic compounds to achieve sustained and controlled release of the substance. The interactions of lipid components existing in the lipid liquid crystals and stratum corneum facilitate the flow of lipids in the stratum corneum and allow the liquid crystal to pass through the cuticle. ${ }^{44}$ Besides, additional agents (such as surfactants and moisturizers) in the lipid liquid crystal can increase skin hydration and reduce the barrier of the cuticle. ${ }^{45}$ Considering that both the lipid liquid crystal and the skin are negatively charged, the substances can penetrate into the skin through the channel formed by the repulsive force. Additionally, the double continuous structure of the lipid liquid crystal contains two intersecting channels, which allows hydrophilic drugs to easily penetrate the lipophilic cuticle. Similar to the structure of the stratum corneum, lipid liquid crystals can enter the skin through hair follicles. Furthermore, lipid liquid crystals have unique in situ biological adhesion and skin affinity by its high viscosity, which can not only augment the skin permeability and skin retention of drugs but also protects the damaged and susceptible parts of the skin. ${ }^{44}$ Collectively, the structure and composition of lipid liquid crystals contribute to promote the substances through the stratum corneum. Strikingly, lipid liquid crystals applied to cosmetic products have good moisturizing effect, skin feeling and physical sunscreen effect by reflecting ultraviolet ray.

\section{Nanocrystals}

Nanocrystals, also known as nanosuspensions, refer to the colloidal dispersion system of pure drug nanoparticles obtained by controlling the particle size, which is characterized by high drug load (nearly 100\%), high oral bioavailability, and good biosecurity. Nanocrystals can significantly improve the solubility and dissolution rate of water-insoluble and fat-insoluble drugs, and is suitable for transdermal administration of insoluble drugs at high dose. ${ }^{46}$ Nanocrystals can form a higher concentration gradient on the skin surface, which facilitates the diffusion of drug molecules into the skin. In addition, nanocrystals 
have good biological adhesion, which can prolong their retention time on the skin surface, help to maintain a high concentration gradient for a long time, and promote the diffusion of drug molecules into the skin. In addition to the intracellular and intercellular routes, nanocrystals can also accumulate in hair follicles to form a drug reservoir. After the nanocrystals dissolve, the drugs diffuse in a concentration-dependent manner into the skin.

\section{Polymer Nanocarriers}

Polymer nanocarriers are a kind of nanocarrier prepared by good biocompatible polymer materials, including polymeric nanoparticles, polymeric micelles, nanohydrogels, nanocapsules, nanospheres and so on. Polymer nanoparticles penetrate skin deep layers mostly through skin appendages including hair follicles and sebaceous glands and can generate a depot effect in these skin regions, where the efficacy components are diffused in a sustained manner into the skin. ${ }^{47}$ Several observations have shown that small-size nanoparticles can penetrate deeper into the bottom of the hair follicle and show more accumulation and stronger penetration, while large-size nanoparticles can only remain at the open end of the hair follicle. In addition to particle size, polymer materials ${ }^{48}$ and surface modification $^{49}$ can also change the permeability promoting ability of polymer nanoparticles. As a reservoir of insoluble drugs, the hydrophobic nucleus of polymer micelles can improve the concentration gradient of insoluble efficacy components in the outer skin and promote the diffusion of efficacy components in the stratum corneum. ${ }^{50}$ The polymer micelles enter the skin in a way similar to polymer nanoparticles and cannot penetrate the stratum corneum in an intact form. The capacity of transdermal drug delivery of the polymer micelles is affected by the affinity between the drug and the hydrophobic nuclear material, and the strong affinity between the two is conducive to achieving high drug loads. However, the high solubilization ability of the polymer micelles prevents drug transfer from the hydrophobic core of the micelles to the skin. Therefore, the design of a polymer micelle system for transdermal drug delivery needs to strike a balance between high drug load and high delivery efficiency. Differing from polymeric nanoparticles and polymeric micelles, nanohydrogels can dramatically enhance skin hydration. Keratinocyte swelling in the skin treated with nanohydrogels was significantly higher than that in the skin treated with water, and the gap between the keratinocyte cells was larger. Besides, increased mobility of the lipid bilayer of the cuticle has also been observed. ${ }^{51}$

\section{Inorganic Nanocarriers}

Inorganic nanocarriers are insoluble or biopersistent nanomaterials with a variety of compositions, structures and properties, including mesoporous silica nanoparticles, titanium dioxide nanoparticles, carbon nanomaterials (such as graphenes, fullerenes and carbon nanotubes), gold nanoparticles, silver nanoparticles and so on. These nanoparticles, characterized by large specific surface area, easy surface modification and good biocompatibility, can penetrate into the deep layer of the epidermal layer and increase its accumulation in the skin, thus being widely used in sunscreen, anti-aging and other functional cosmetic products. ${ }^{52-55}$ However, the mechanism of percutaneous administration of distinct inorganic nanoparticles is different. For example, the interaction between gold nanoparticles and skin cuticle lipids can induce a transient and reversible opening in the stratum corneum, which allows them to penetrate into the skin and accumulate in the active epidermis where they are captured by Langerhans cells and generate an immune response. ${ }^{56}$ In addition, mechanism of skin permeation of drug from diverse carbon nanotubes-based formulations such as electrically tuneable carbon nanotubes films, hydrogels, and carbon nanotubes polymer composite microneedles is distinct, which is shown in detail in Figure $4 .^{57}$ The transdermal delivery mechanisms of graphenes and fullerenes is similar to the carbon nanotubes.

\section{Application and Efficacy Evaluation of Active Cosmetic Ingredient Nanocarriers \\ Skin Moisturizing Efficacy Components Nanocarriers}

Skin problems and skin diseases are associated with epidermal barrier dysfunction. Epidermal barrier dysfunction can cause skin to lose a lot of water, resulting in dry, sensitive, itchy, chapped skin. Studies have shown that the nanocarriers with skin moisturizing efficacy components can effectively increase the epidermal moisture content and restore the skin barrier function, which can not only solve the skin problems but also have a preventive and therapeutic effect on chronic skin diseases such as eczema, atopic dermatitis and psoriasis. ${ }^{58-60}$ 
A

\section{Electro responsive films}

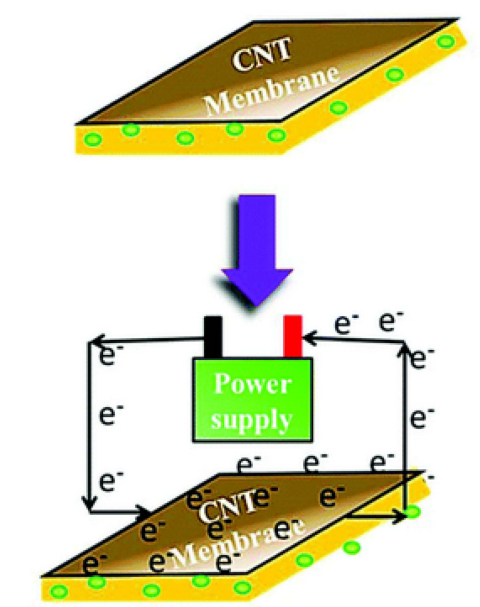

B
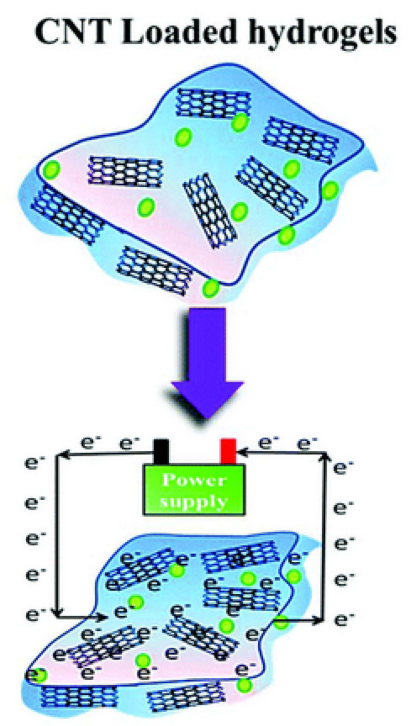

C

\section{Drug-polymer loaded microneedle's}

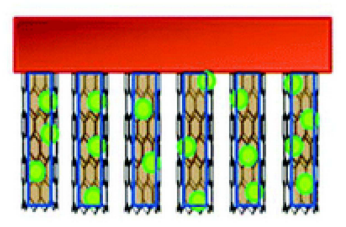

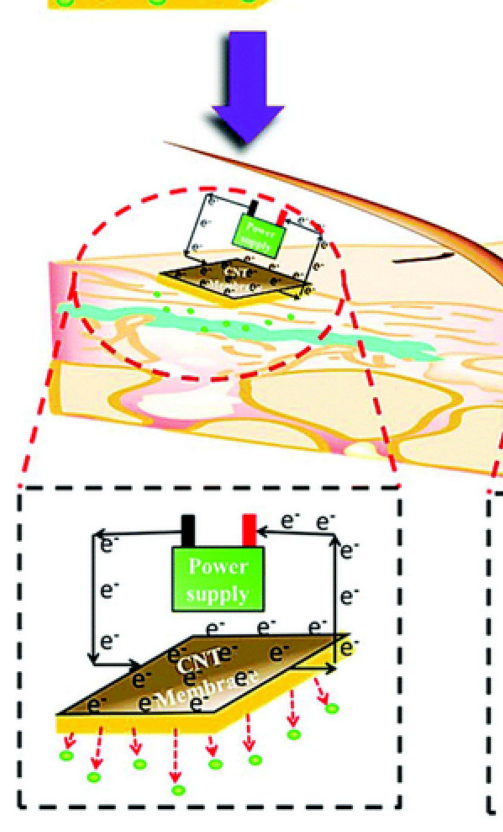

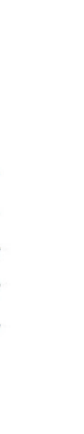

Figure 4 Mechanism of skin permeation of drug from carbon nanotubes-based formulations including electrically tuneable carbon nanotubes films, hydrogels, and carbon nanotubes polymer composite microneedles.

Notes: (A) Carbon nanotube membrane would be either covered or loaded with pure drug alone; upon application of voltage, it forces the drug to permeate through the tough stratum corneum. (B) Due to the incorporation of carbon nanotube, the conductance capacity of carbon nanotube hydrogels has been enhanced, which compels the drug to permeate through the skin to reaching the desired site of action. (C) Carbon nanotube-microneedles provide an excess mechanical strength to penetrate skin and governs the drug release profile which is completely dependent on the degradation mechanism and kinetics of the polymer. Reprinted from Kuche K, Maheshwari R, Tambe V, et al. Carbon nanotubes (CNTs) based advanced dermal therapeutics: current trends and future potential. Nanoscale. 2018;10(19):891 I-8937. ${ }^{57}$ Copyright (20I8), with permission from Royal Society of Chemistry.

Hyaluronic acid is a major component of the extracellular matrix in the active epidermis and dermis. It has the effect of moisturizing and repairing the skin but cannot enter deep skin owing to its large molecular weight. Chen et $\mathrm{al}^{61}$ prepared an ethosomal carrier system encapsulating hyaluronic acid. Compared to PBS control, the system enhanced penetration of hyaluronic acid into the active epidermis and dermis by disrupting the dense structure of the stratum corneum. Concentrations of hyaluronic acid in skin were about 1000 -fold higher than those in blood. Ming et $\mathrm{al}^{62}$ developed an alcohol-free oil/water hyaluronic acid nanoemulsions with desirable skin permeable capacity. The nanoemulsions penetrated across stratum corneum and diffused deeper into dermis by follicular 
and intercellular route to delivery hyaluronic acid. Its penetration mechanism be closely associated with transmembrane concentration gradient, carrier characteristics and penetration enhancers. One of the major intercellular lipid matrix of the stratum corneum is ceramide that acts as a binding agent with proteins on the cell surface through ester bonds and forms a physiological barrier in the epidermis to prevent water loss and protect against external stimuli. ${ }^{63}$ As a high crystalline substance, it is difficult for ceramide to be used in cosmetics due to its low solubility, poor water dispersion and easy crystallization. Yilmaz and Borchert $^{64}$ developed a positively charged nanoemulsions containing ceramides. The stability and solubility of ceramides were significantly improved by incorporating in the positively charged nanoemulsions.

Natural vegetable oil has been widely used in cosmetics due to their antioxidant, hydration, anti-aging, and protection properties on the skin. ${ }^{65,66}$ Bernardi et al ${ }^{58}$ created rice bran oil nanoemulsions using low energy emulsification methods. This formulation has no skin irritation and can significantly improve skin moisture. After 14 days of application by rice bran oil nanoemulsions, skin moisture increased by $38 \%$ in normal control volunteers and by $30 \%$ in patients with atopic dermatitis or psoriasis. Tichota et $\mathrm{al}^{67}$ used argan oil as liquid lipid to prepare nanostructured lipid carriers and further prepared nanostructured lipid carriers-based hydrogel formulation. The formulation has high stability, firmness and adhesion, and can extend the contact time for topical application. The in vivo evaluation of the skin illustrated that the formulation precipitated an increase in skin hydration by a synergistic effect of nanostructured lipid carriers occlusion plus argan oil hydration and showed a tendency to enhance moisture retention over time.

\section{Whitening and Freckle-Removing Efficacy Components Nanocarriers}

The synthesis of melanin is the result of a series of oxidation reactions in which tyrosinase is the key enzyme. At present, whitening and freckle-removing efficacy components in cosmetics are mainly through inhibition of melanocyte proliferation, inhibition of tyrosinase and other related rapid-limiting enzyme activity and inhibition of melanosome migration, so as to achieve whitening and freckle-removing effect. However, there are generally the following problems in the application of these efficacy components: (i) efficacy components have poor solubility, poor stability, and are easy to decompose and discolor when exposed to light and heat, (ii) due to the skin barrier, whitening efficacy components are difficult to penetrate into the target part (stratum basale) and unable to act on target cells (melanin cells), resulting in low whitening efficiency, (iii) certain whitening efficacy components have strong skin irritation at high doses, (iv) whitening efficacy components are single and lack the synergistic effect of efficacy ingredients of different action mechanism. The technology of nanocarriers solves the above problems well. The investigations indicate that the stability and whitening and freckle-removing efficacy of these efficacy components are significantly improved after being loaded on the nanocarriers.

Phenylethyl resorcinol is a new whitening agent with the ability to inhibit tyrosinase activity and has been applied in cosmetics as a whitening and brightening efficacy component. ${ }^{68}$ However, the light instability and poor water solubility of phenylethyl resorcinol limit its application. Kim et al ${ }^{69}$ prepared a phenylethyl resorcinol-loaded nanostructured lipid carriers by the hot-melted ultrasonic method. The incorporation of phenylethyl resorcinol into nanostructured lipid carriers conferred excellent physicochemical stability and photo stability and revealed a sustained release. Nanostructured lipid carriers could efficiently promote the uptake of phenylethyl resorcinol by melanocyte in epidermis to inhibit of melanosome migration, thus achieving the whitening effect. N-AcetylD-Glucosamine, a precursor of hyaluronic acid, can preserve the skin hydration and is used for topical treatment of hyperpigmentation disorders because of its inhibitory effect on tyrosinase enzymes in melanocytes, which shows a broad prospect in the application of whitening skin care products. Unfortunately, it is barely absorbed by the skin. The solid lipid nanoparticles allowed a higher N-AcetylD-Glucosamine permeation through the stratum corneum compared to the free N-Acetyl-D-Glucosamine to contributing to the improvement of skin properties. ${ }^{70} 4-n-$ Butylresorcinol has an inhibitory effect on melanogenesis by directly inhibiting the activity of tyrosinase and tyrosinase-related protein-1 but can induce skin irritation, particularly in high concentrations. 4-n-Butylresorcinol can reduce melanin synthesis by directly inhibiting the activity of tyrosinase and tyrosinase-related protein-1 but can induce skin irritation, particularly in high concentrations. Liposomes improved stabilization and enhanced penetration of 4-n-butylresorcinol. Liposome encapsulating 4-nbutylresorcinol was well tolerated without any adverse 
reactions such as skin irritation and significantly reduced the skin melanin content when used to treat patients with chloasma for 8 weeks. ${ }^{71}$ Except to bind directly to the tyrosinase, resveratrol can regulate various melanogenic signaling molecules to inhibit melanogenesis. Several observations illustrated that liposomes encapsulating 4-nbutylresorcinol and resveratrol have a synergistic effect the treatment of melasma with its effect appearing as early as 2 weeks. $^{72}$

In addition, the plant source whitening agents such as paeonol, glabridin, resveratrol and curcumin can also effectively inhibit the tyrosinase activity but are difficult to add to the cosmetic formulations in an effective dose due to their poor water dispersibility. Nanocarriers significantly increase the load of efficacy components. Using pigmentation guinea pigs as models, Li et $\mathrm{al}^{73}$ found that the whitening effect of paeonol lipid liquid crystals was comparable to that of commercial hydroquinone cream, but its skin irritation was less than that of hydroquinone cream and commercial paeonol ointment.

\section{Anti-Aging Efficacy Components Nanocarriers}

Skin aging is related to the accumulation of excess oxygen-free radicals in human body. Timely scavenging of excess oxygen-free radicals is an effective means to prevent diseases and delay skin aging. At present, the antiaging ingredients commonly used in cosmetics can effectively eliminate oxygen-free radicals, but there are some problems in practical application, such as poor stability, low bioavailability, the decomposition under light, heat, and oxygen, and difficulty in transdermal absorption. The emergence of nanocarriers with anti-aging efficacy components has provided the possibility to solve these problems.

Considering the safety of cosmetic efficacy components, the natural active ingredients with antioxidant and free radical scavenging properties such as polyphenols, flavonoids and carotenoids are widely used in cosmetics (Table 2). Tocopherol is sensitive to light and easy to be oxidized. Nanostructured lipid carriers significantly enhance the stability of tocopherol, and makes it stay in the epidermis at a high concentration to achieve efficient moisturizing and antioxidant effects. ${ }^{74}$ Madecassoside is difficult to be absorbed by the skin due to its polarity and large molecular weight. Liposomes can promote madecassoside to penetrate epidermis and remain or release at dermis, which prevents it from entering the blood circulation and causing systemic adverse reactions. ${ }^{75}$ The utilization of astaxanthin, a natural pigment carotenoid with remarkable antioxidant activity, is limited due to its low water solubility and poor chemical stability. Compared with the free astaxanthin, solid lipid nanoparticles or nanoemulsions significantly enhanced the chemical stability of astaxanthin, even under a variety of external stimulation, and provided a long release in a simulated vivo environment. $^{76,77}$

Of note, the high antioxidant capacity of inorganic nanocarriers has attracted the attention of researchers. Lens et $\mathrm{al}^{78}$ prepared novel organofullerenes by encapsulating fullerene- $\mathrm{C}_{60}$ and synthesized fulleropyrrolidine derivatives into multilamellar phospholipid liposomes. The novel organofullerenes increased the efficiency of delivery of fullerenes to target tissues by enhancing their water solubility and showed better antioxidative characteristics for hydroxyl radical and superoxide radical compared with fullerene- $\mathrm{C}_{60}$ and its derivatives. Ito et $\mathrm{al}^{79}$ investigated the antioxidant effects of fullerene in ultraviolet B-induced disorders in mouse skin. In comparison with the control, the co-application of fullerene and ascorbic acid could effectively suppress the oxidative damage of skin and significantly decrease erythema, the reactive oxygen species index and apoptosis index in mouse skin after ultraviolet B irradiation.

\section{Anti-Acne Efficacy Components Nanocarriers}

Acne vulgaris (acne) is a common and chronic inflammatory dermatoses of the pilosebaceous units. ${ }^{80}$ The main causes of the development of acne include hyperactivity of the sebaceous gland, follicular epidermal hyperproliferation and inflammation of pilosebaceous units caused by pathogens such as Cutibacterium acnes (C. acnes). ${ }^{81}$ Although topical therapy is considered the first option in the management of mild and moderate acne, physical and chemical properties of drugs such as skin irritation and low permeability limited their applications, which provides an enormous opportunity for the nanocarrier technology in designing of a novel, low-dose and effective treatment systems to control acne disease. ${ }^{82}$

Adapalene, a chemical of third-generation retinoid, has been commercially available in the form of topical gel and cream for the treatment of mild to moderate acne. However, the therapy of topical adapalene suffers the 
most common side effect characterized by scaling, dryness, erythema and a burning sensation in the area of application. $^{83}$ Guo et $\mathrm{al}^{84}$ developed an acid-responsive polymeric nanocarriers encapsulating adapalene via nanoprecipitation. The in vivo and in vitro experiment revealed that the adapalene-loaded polymeric nanocarriers appear to be as efficient as the commercial product Transcutol ${ }^{\circledR}$. Notably, the nanocarrier system realized the on-demand delivery and skin-irritation reduction of drug by using the acidic microenvironment of acne skin. In another study, the nanoemulsion gel formulation containing adapalene seems to be more efficacious and better tolerated than the conventional gel formulation for the treatment of patients with acne. ${ }^{85}$

In addition to synthetic chemicals, the research and application of plant ingredients with antibacterial, anti-inflammatory and scar removing effects in anti-acne cosmetics has been gradually increasing due to the safety limitations of cosmetic hygiene standards on the anti-acne cosmetic ingredients. Lauric acid, a natural free fatty acid, have been revealed to be strong antibacterial activity against $C$. acnes but less harmful than the synthetic antimicrobial chemicals. ${ }^{86}$ Pornpattananangkul et $\mathrm{al}^{87}$ developed liposomal lauric acids (LipoLA) by loading lauric acids into the lipid bilayer of liposomes. LipoLA not only well preserved the bactericidal property against $C$. acnes but also readily fused with bacterial membranes, which led to more effective killing of $C$. acnes by destroying bacterial membrane structures. Subsequently, topical application of LipoLA in a gel form onto the infectious skin sites eradicated $C$. acnes bacteria in vivo and did not induce acute skin toxicity. Curcumin, isolated from the spice turmeric, can inhibit the growth of $C$. acnes but is limited in use because of low aqueous solubility and poor bioavailability. ${ }^{88}$ Microemulsions loading curcumin significantly improved its physicochemical properties and could efficiently accumulate in the skin, which caused the formation of curcumin reservoir to suppress C. acnes in vitro. ${ }^{89}$ The observations highlight the potential of harnessing nanocarriers containing plant ingredients as an alternative treatment for acne vulgaris.

Recently, oxidative stress has been disclosed to play a vital role in acne formation, hinting that oxygen radical scavengers are potential anti-acne agents. ${ }^{90}$ Fullerene, a spherical carbon molecule with strong radical sponge activity can penetrate deep into the epidermis without causing skin irritation. ${ }^{91}$ Inui et al ${ }^{92}$ topically applied fullerene gel onto the skin with acne lesions twice a day in an open trial. Erythematous papules and pustules significantly decreased by suppressing sebum in the inflammatory response and by reducing $C$. acnes lipase activity and the water content of the skin significantly increased after treatment for 8 weeks, implicating that the fullerene gel may control acne vulgaris with skin care benefit.

\section{Anti-Alopecia Efficacy Components Nanocarriers}

Hair loss is associated with different diseases, nutritional deficiency, aging, hormone imbalance, and stress. ${ }^{93}$ It is generally not a life-threatening event but potentially affects social interactions and the psychological wellbeing of patients. ${ }^{94}$ The main approach of treatment of hair loss in the clinical setting is the topical application of antialopecia agents. Recently, new formulation productions have been developed through nanocarrier technology, which notably alleviates the side effects of direct application of anti-alopecia agents in the affected area.

Minoxidil, a pyridine-derivative, is widely used for the treatment of androgenic alopecia. Commercial products containing minoxidil are usually solutions with high percentage of ethyl alcohol and/or propylene glycol and are recommended as proper use in twice-daily applications. However, repeated applications of high ethyl alcohol and/ or propylene glycol content products lead to severe adverse effects. Mura et $\mathrm{al}^{95}$ showed alcohol-free liposomal formulations potential as minoxidil topical delivery in hair loss treatment by enhancing its skin penetration. Balakrishnan et $\mathrm{al}^{96}$ indicated that niosomal formulations of minoxidil have a good potential for drug cutaneous targeting with regards to process variables. In another study, minoxidil-loading solid lipid nanoparticles suspensions have been shown as efficient as commercial solutions for skin penetration; and were non-corrosive while commercial solutions presented a corrosive potential. ${ }^{97}$ These data suggested that nanocarriers would be a promising application for hair loss treatment. In addition, applications of the phytobioactive ingredients with antialopecia property into nanocarriers also have a good effect (Table 2).

\section{Sunscreen Efficacy Components Nanocarriers}

Sunscreen efficacy ingredients can prevent skin from damage by absorbing and reflecting ultraviolet light, thus reducing the occurrence of light linear disease and light aging. ${ }^{98}$ Considering synthesized by chemical ultraviolet 
absorbers, they generally have the disadvantages of large skin irritation and poor light stability. However, these challenges could be well solved by loading sunscreen efficacy components into nanocarriers.

Octyl methoxycinnamate is a widely used sunscreen characterized by potent ultraviolet-B absorbing properties but its applications are limited by photoinstability and potential skin permeation. Octyl methoxycinnamate in liposomes has a greater skin accumulation but a lower penetration into the deeper skin layers, which lead to a slightly better sun protection factor and more remains in the stratum corneum compared to a conventional formulation. ${ }^{99}$ In another study, octyl methoxycinnamate was loaded into the pores of the mesoporous silicate MCM-41 and then entrapped there by plugging the pore openings. The MCM-41 inclusion product allows a remarkable improvement of sunscreen photostability, broader photoprotection range and negligible sunscreen release. ${ }^{100}$ Besides, nanocapsules or transfersomes coating octyl methoxycinnamate has a similar effect. ${ }^{101}$ Benzophenone-3, a lipophilic chemical absorber absorbing both ultraviolet $\mathrm{B}$ and short ultraviolet $\mathrm{A}$, is classified as a safe and effective, over-the-counter sunscreen agent by the Food and Drug Administration. It has a poor sunscreen effect at concentrations less than $5 \%$, but can trigger photosensitivity in high dose and be absorbed by the skin leading to toxic side effects. Compared with w/o microemulsions containing benzophenone-3, the w/o microemulsions were more suitable for topical delivery of the sunscreen due to low transdermal uxes and release rates.102 Strikingly, nanocarriers loading the sunscreen properties of herb such as safranal and similar derivatives could exert good sunscreen activity. ${ }^{59}$

In addition to improving the properties of sunscreen ingredients, nanocarriers can also effectively improve the sunscreen efficiency. Compared with conventional sunscreen gel or emulsion formulations, the sunscreen formulation containing nanocapsules a better sunscreen effect. Sunscreen efficacy components can be quickly dispersed from the nanocapsules to the cuticle surface and the extremely high specific surface area of the nanocapsules makes it more effective in covering the skin against ultraviolet radiation. ${ }^{103}$ Furthermore, certain nanocarriers such as solid lipid nanoparticles and titanium dioxide nanoparticles have the properties of reflecting and scattering ultraviolet rays and can act as a physical sunscreen agent, synergistic effect with the sunscreen efficacy components to enhance the sunscreen effect. ${ }^{104}$

\section{Multiple Functional Components Codelivery Nanocarriers}

Skin problems and skin diseases are often not caused by a single factor. Mutual coordination or joint effect of multiple functional ingredients can play a better effect of sunscreen and skin care. 2-ethylhexyl trans-4-methoxycinnamate, 2ethylhexyl-2-cyano-3,3-diphenylacrylate and bis-ethylhexyloxyphenol methoxyphenyl triazine are three molecular sunscreens, which can absorb different wavelengths of ultraviolet light but have the side effects in high dose. The solid lipid nanoparticles loading three molecular sunscreens improved their photostability and enhanced the sun protection factor values by more than twice in comparison with free samples. It also obtained a lower allergenic potential by using less than half of maximum admitted concentration imposed by International Agency of Food and Drug Administration regulations $(10 \%) .{ }^{105}$ The bioactive peptides such as antioxidative peptides, signal peptides and neurotransmitter inhibitor peptides can regulate many biological processes with relevance to skin aging but are different in the mechanism of action. The liposomes coating three bioactive peptides showed high encapsulation efficiency, high loading capacity and sustained release. Application of the nanoliposomes in face led to a remarkable reduction of the volume, area and area ratio of wrinkles, and an improvement of skin elasticity by reducing $\mathrm{H}_{2} \mathrm{O}_{2}$-induced oxidative stress damage, inhibiting catecholamine release and increasing their expression levels of type I collagen and hyaluronic acid. ${ }^{12}$ In addition, the codelivery of multiple plant active ingredients has also attracted great attention (Table 2).

Intriguing, certain inorganic nanoparticles such as fullerene- $\mathrm{C}_{60}$ and gold nanoparticles have dual properties. In addition to being nanocarriers, they are regarded as special cosmetic efficacy components due to their antibacterial or antioxidant ability. Nanofiber face mask containing ascorbic acid, retinoic acid, collagen and gold nanoparticles presented a well anti-wrinkle property because of its high surface area- to-volume ratio enhancing the skin permeation of efficacy components. ${ }^{106}$ In another study, LipoFullerene cream containing fullerene- $\mathrm{C}_{60}$ dissolved in squalane remarkably enhanced the skin moisture and the repressive-wrinkle formation when compared with squalane blended cream (without fullerene- $\mathrm{C}_{60}$ ). ${ }^{107}$

\section{Summary and Prospect}

The application of nanocarrier technology in functional cosmetics not only improves the stability and solubility 
of efficacy components but also overcomes the barrier effect of cuticle, which enables the active cosmetic ingredients to enter the target site of the skin and realize the functions of sustained release, controlled release and longterm release, thus solving various skin problems and skin diseases. Compared with conventional cosmetic preparations, the formulation and preparation process of nanocarriers are more complicated. The properties, dosage and proportion of each component in the formulation as well as the preparation process affect the surface charge, internal structure, interaction with efficacy components, stability and skin permeability of the nanocarriers. There are still many problems to be solved in the large-scale production and product application of some nanocarriers, such as Ostward ripening in the preparation of nanoemulsions and nanocrystals, drug leakage and material degradation of liposomes, and lipid crystallization and polycrystalline transformation inducing particle aggregation in lipid nanoparticles. Moreover, the nanocarriers are not the final cosmetic dosage form, but also needs to be further processed into appropriate cosmetic dosage form, such as cream, emulsion and gel. The addition of excipients required for these dosage forms increases the difficulty of quality control, and may cause problems such as nanocarrier particle size change and drug leakage, thus affecting its skincare efficacy. Therefore, the formulation optimization, quality research, preparation technology research and the development of special preparation equipment are important directions of research and development for the application of nanocarrier technology in the field of cosmetics.

The application of nanocarrier technology in the field of cosmetics presents a great prospect but also faces many challenges. Firstly, the biosafety and skin toxicity of nanocarriers in cosmetics should be paid more attention. For example, the immunogenicity of the polymer materials used to prepare nanocarriers should be concerned. Dendritic polymers rich in amino have a large amount of surface positive charge, which leads to potential cytotoxicity. The formation of microemulsions requires high concentrations of surfactants, which may irreversibly alter the stratum corneum structure for long-term application, resulting in skin irritation. In addition, with the application of inorganic nanomaterials (such as mesoporous silica nanoparticles, titanium dioxide nanoparticles, fullerenes and graphenes) in the fields of functional cosmetics, the absorption and accumulation of skin and hair follicles and metabolism and toxicology in vivo deserve attention. ${ }^{108}$
Secondly, there are few reports on the distribution, sustained/controlled release behavior, metabolic pathways and products, and metabolic kinetics of nanocarriers in the skin. Therefore, it is necessary to carry out systematic and in-depth research on the skin toxicology and skin metabolic kinetics of nanocarriers used in functional cosmetics, and to understand their influencing factors and mechanism of action, which will provide a solid theoretical and experimental basis for the comprehensive application of nanotechnology in the field of functional cosmetics.

The application of nanocarrier technology in functional cosmetics is a new platform for dermal/transdermal drug delivery, which greatly promotes the development of dermal/transdermal drug delivery. With the breakthrough in preparation technology, quality control, promoting permeability mechanism and safety evaluation, it can be expected that there will be a new nanocarrier of functional cosmetics on the market in the future. In addition, while developing the nanocarrier technology for functional cosmetics, it is necessary to improve the construction of regulations and establish a standardized evaluation system for effectiveness and safety, which promotes the healthy development of nanocarrier technology in the field of cosmetics.

\section{Acknowledgments}

We would like to thank all the members of Liu' Group who assisted in valuable suggestions on this manuscript.

\section{Author Contributions}

All authors made a significant contribution to the work reported, whether that is in the conception, study design, execution, acquisition of data, analysis and interpretation, or in all these areas; took part in drafting, revising or critically reviewing the article; gave final approval of the version to be published; have agreed on the journal to which the article has been submitted; and agree to be accountable for all aspects of the work.

\section{Funding}

This work was supported by the National Natural Science Foundation of China (31470968) and National key R \& D program of Nanotechnology of China (2020YFA0710700).

\section{Disclosure}

The authors report no conflicts of interest in this work. 


\section{References}

1. Santos AC, Morais F, Simões A, et al. Nanotechnology for the development of new cosmetic formulations. Expert Opin Drug Deliv. 2019;16(4):313-330. doi:10.1080/17425247.2019.1585426

2. Chariou PL, Ortega-Rivera OA, Steinmetz NF. Nanocarriers for the delivery of medical, veterinary, and agricultural active ingredients. ACS Nano. 2020;14(3):2678-2701. doi:10.1021/ acsnano.0c00173

3. Müller-Goymann CC. Physicochemical characterization of colloidal drug delivery systems such as reverse micelles, vesicles, liquid crystals and nanoparticles for topical administration. Eur $J$ Pharm Biopharm. 2004;58(2):343-356. doi:10.1016/j. ejpb.2004.03.028

4. Lohani A, Verma A, Joshi H, Yadav N, Karki N. Nanotechnology-based cosmeceuticals. ISRN Dermatology. 2014;2014(May):1-14. doi:10.1155/2014/843687

5. Kaul S, Gulati N, Verma D, Mukherjee S, Nagaich U. Role of nanotechnology in cosmeceuticals: a review of recent advances. $J$ Pharm. 2018;2018:1-19.

6. Lohani A, Verma A. Vesicles: potential nano carriers for the delivery of skin cosmetics. J Cosmet Laser Ther. 2017;19 (8):485-493. doi:10.1080/14764172.2017.1358451

7. Chermahini SH, Adibah F, Majid A, Sarmidi MR. Cosmeceutical value of herbal extracts as natural ingredients and novel technologies in anti-aging. J Med Plants Res. 2011;5(14):3074-3077.

8. Marzuki NHC, Wahab RA, Hamid MA. An overview of nanoemulsion: concepts of development and cosmeceutical applications. Biotechnol Biotechnol Equip. 2019;33(1):779-797. doi:10.1080/13102818.2019.1620124

9. Ganesan P, Choi DK. Current application of phytocompoundbased nanocosmeceuticals for beauty and skin therapy. Int $J$ Nanomedicine. 2016;11:1987-2007. doi:10.2147/IJN.S104701

10. Hara Y, Hirao T, Iwai I. Facial expression under stiff stratum corneum leads to strain concentrations, followed by residual wrinkle formation. Int $J$ Cosmet Sci. 2017;39(1):66-71. doi:10.1111/ics. 12349

11. Kammeyer A, Luiten RM. Oxidation events and skin aging. Ageing Res Rev. 2015;21:16-29. doi:10.1016/j.arr.2015.01.001

12. Han F, Luo D, Qu W, et al. Nanoliposomes codelivering bioactive peptides produce enhanced anti-aging effect in human skin. $J$ Drug Deliv Sci Technol. 2020;57(March):101693. doi:10.1016/j. jddst.2020.101693

13. Scicluna MC, Vella-Zarb L. Evolution of nanocarrier drug-delivery systems and recent advancements in covalent organic framework-drug systems. ACS Appl Nano Mater. 2020;3(4):30973115. doi:10.1021/acsanm.9b02603

14. Palmer BC, DeLouise LA. Nanoparticle-enabled transdermal drug delivery systems for enhanced dose control and tissue targeting. Molecules. 2016;21(12):7-9.

15. Patzelt A, Knorr F, Blume-Peytavi U, Sterry W, Lademann J. Hair follicles, their disorders and their opportunities. Drug Discov Today Dis Mech. 2008;5(2):173-181. doi:10.1016/j. ddmec.2008.04.006

16. Lauterbach A, Müller-Goymann CC. Applications and limitations of lipid nanoparticles in dermal and transdermal drug delivery via the follicular route. Eur J Pharm Biopharm. 2015;97:152-163. doi:10.1016/j.ejpb.2015.06.020

17. Vogt A, Combadiere B, Hadam S, et al. $40 \mathrm{~nm}$, but not 750 or $1500 \mathrm{~nm}$, nanoparticles enter epidermal CD1a+ cells after transcutaneous application on human skin. $J$ Invest Dermatol. 2006;126(6):1316-1322. doi:10.1038/sj.jid.5700226

18. Główka E, Wosicka-Frąckowiak H, Hyla K, et al. Polymeric nanoparticles-embedded organogel for roxithromycin delivery to hair follicles. Eur J Pharm Biopharm. 2014;88(1):75-84. doi:10.1016/j.ejpb.2014.06.019
19. Marianecci C, Di Marzio L, Rinaldi F, et al. Niosomes from 80 s to present: the state of the art. Adv Colloid Interface Sci. 2014;205:187-206.

20. Sun M, Fan A, Wang Z, Zhao Y. Dendrimer-mediated drug delivery to the skin. Soft Matter. 2012;8(16):4301-4305. doi: $10.1039 / \mathrm{c} 2 \mathrm{sm} 07280 \mathrm{~g}$

21. McClements DJ. Nanoemulsions versus microemulsions: terminology, differences, and similarities. Soft Matter. 2012;8(6):17191729. doi:10.1039/C2SM06903B

22. Kreilgaard M. Influence of microemulsions on cutaneous drug delivery. Adv Drug Deliv Rev. 2002;54(SUPPL).

23. Bolko K, Zvonar A, Gašperlin M. Mixed lipid phase SMEDDS as an innovative approach to enhance resveratrol solubility. Drug Dev Ind Pharm. 2014;40(1):102-109. doi:10.3109/03639045.2012.749888

24. Yuan JS, Yip A, Nguyen N, Chu J, Wen X-Y, Acosta EJ. Effect of surfactant concentration on transdermal lidocaine delivery with linker microemulsions. Int $J$ Pharm. 2010;392(1-2):274-284. doi:10.1016/j.jpharm.2010.03.051

25. Gannu R, Palem CR, Yamsani VV, Yamsani SK, Yamsani MR. Enhanced bioavailability of lacidipine via microemulsion based transdermal gels: formulation optimization, ex vivo and in vivo characterization. Int $J$ Pharm. 2010;388(1-2):231-241. doi:10.1016/j.jpharm.2009.12.050

26. Zhang Y-T, Huang Z-B, Zhang S-J, et al. In vitro cellular uptake of evodiamine and rutaecarpine using a microemulsion. Int $J$ Nanomedicine. 2012;7:2465-2472. doi:10.2147/IJN.S30616

27. Lane ME. Skin penetration enhancers. Int J Pharm. 2013;447(12):12-21. doi:10.1016/j.ijpharm.2013.02.040

28. Lademann J, Knorr F, Richter H, et al. Hair follicles-an efficient storage and penetration pathway for topically applied substances. Summary of recent results obtained at the center of experimental and applied cutaneous physiology, Charité -Universitätsmedizin Berlin, Germany. Skin Pharmacol Physiol. 2008;21(3):150-155. doi:10.1159/000131079

29. Wu H, Ramachandran C, Weiner ND, Roessler BJ. Topical transport of hydrophilic compounds using water-in-oil nanoemulsions. Int J Pharm. 2001;220(1-2):63-75. doi:10.1016/S0378-5173(01) 00671-8

30. Singh Y, Meher JG, Raval K, et al. Nanoemulsion: concepts, development and applications in drug delivery. $J$ Control Release. 2017;252:28-49. doi:10.1016/j.jconrel.2017.03.008

31. Sala M, Diab R, Elaissari A, Fessi H. Lipid nanocarriers as skin drug delivery systems: properties, mechanisms of skin interactions and medical applications. Int J Pharm. 2018;535(1-2):1-17. doi:10.1016/j.ijpharm.2017.10.046

32. Kim J-E, Oh G-H, Jang G-H, Kim Y-M, Park Y-J. Transformerethosomes with palmitoyl pentapeptide for improved transdermal delivery. $J$ Drug Deliv Sci Technol. 2019;52 (November2018):460-467. doi:10.1016/j.jddst.2019.04.039

33. Tan X, Fang Y, Ren Y, et al. D- $\alpha$-tocopherol polyethylene glycol 1000 succinate-modified liposomes with an siRNA corona confer enhanced cellular uptake and targeted delivery of doxorubicin via tumor priming. Int $J$ Nanomedicine. 2019;14:1255-1268. doi:10.2147/IJN.S191858

34. Abd El-Alim SH, Kassem AA, Basha M, Salama A. Comparative study of liposomes, ethosomes and transfersomes as carriers for enhancing the transdermal delivery of diflunisal: in vitro and in vivo evaluation. Int $J$ Pharm. 2019;563(March):293-303. doi:10.1016/j.ijpharm.2019.04.001

35. Shen LN, Zhang YT, Wang Q, Xu L, Feng NP. Enhanced in vitro and in vivo skin deposition of apigenin delivered using ethosomes. Int $J$ Pharm. 2014;460(1-2):280-288. doi:10.1016/j. ijpharm.2013.11.017

36. Du Plessis J, Egbaria K, Ramachandran C, Weiner N. Topical delivery of liposomally encapsulated gamma-interferon. Antiviral Res. 1992;18(3-4):259-265. doi:10.1016/0166-3542(92)90059-E 
37. Raber AS, Mittal A, Schäfer J, et al. Quantification of nanoparticle uptake into hair follicles in pig ear and human forearm. J Control Release. 2014;179:25-32. doi:10.1016/j.jconrel.2014.01.018

38. Schäfer-Korting M, Mehnert W, Korting HC. Lipid nanoparticles for improved topical application of drugs for skin diseases. $A d v$ Drug Deliv Rev. 2007;59(6):427-443. doi:10.1016/j. addr.2007.04.006

39. Cevc G. Lipid vesicles and other colloids as drug carriers on the skin. Adv Drug Deliv Rev. 2004;56(5):675-711. doi:10.1016/j. addr.2003.10.028

40. Wissing SA, Müller RH. The influence of solid lipid nanoparticles on skin hydration and viscoelasticity - in vivo study. Eur $J$ Pharm Biopharm. 2003;56(1):67-72. doi:10.1016/S0939-6411 (03)00040-7

41. Elsayed MMA, Abdallah OY, Naggar VF, Khalafallah NM. Lipid vesicles for skin delivery of drugs: reviewing three decades of research. Int $J$ Pharm. 2007;332(1-2):1-16. doi:10.1016/j. ijpharm.2006.12.005

42. Kakadia PG, Conway BR. Solid lipid nanoparticles for targeted delivery of triclosan into skin for infection prevention. $J$ Microencapsul. 2018;35(7-8):695-704. doi:10.1080/ 02652048.2019 .1576796

43. Müller RH, Petersen RD, Hommoss A, Pardeike J. Nanostructured lipid carriers (NLC) in cosmetic dermal products. Adv Drug Deliv Rev. 2007;59(6):522-530. doi:10.1016/j. addr.2007.04.012

44. Rajabalaya R, Musa MN, Kifli N, David SR. Oral and transdermal drug delivery systems: role of lipid-based lyotropic liquid crystals. Drug Des Devel Ther. 2017;11:393-406. doi:10.2147/ DDDT.S103505

45. Rattanapak T, Young K, Rades T, Hook S. Comparative study of liposomes, transfersomes, ethosomes and cubosomes for transcutaneous immunisation: characterisation and in vitro skin penetration. J Pharm Pharmacol. 2012;64(11):1560-1569. doi:10.1111/ j.2042-7158.2012.01535.x

46. Zhai X, Lademann J, Keck CM, Müller RH. Nanocrystals of medium soluble actives - novel concept for improved dermal delivery and production strategy. Int J Pharm. 2014;470(12):141-150. doi:10.1016/j.ijpharm.2014.04.060

47. Kahraman E, Güngör S, Özsoy Y. Potential enhancement and targeting strategies of polymeric and lipid-based nanocarriers in dermal drug delivery. Ther Deliv. 2017;8(11):967-985. doi:10.4155/tde-2017-0075

48. Cheng CJ, Tietjen GT, Saucier-Sawyer JK, Saltzman WM. A holistic approach to targeting disease with polymeric nanoparticles. Nat Rev Drug Discov. 2015;14(4):239-247. doi:10.1038/ nrd4503

49. Hasanovic A, Zehl M, Reznicek G, Valenta C. Chitosan-tripolyphosphate nanoparticles as a possible skin drug delivery system for aciclovir with enhanced stability. $J$ Pharm Pharmacol. 2009;61(12):1609-1616. doi:10.1211/jpp.61.12.0004

50. Yotsumoto K, Ishii K, Kokubo M, Yasuoka S. Improvement of the skin penetration of hydrophobic drugs by polymeric micelles. Int $J$ Pharm. 2018;553(1-2):132-140. doi:10.1016/j.ijpharm.2018.10.039

51. Giulbudagian M, Rancan F, Klossek A, et al. Correlation between the chemical composition of thermoresponsive nanogels and their interaction with the skin barrier. $J$ Control Release. 2016;243:323-332. doi:10.1016/j.jconrel.2016.10.022

52. Hsiao PF, Tsai HC, Peng S, et al. Transdermal delivery of poly (ethylene glycol)-co-oleylamine modified gold nanoparticles: effect of size and shape. Mater Chem Phys. 2019;224 (November2018):22-28. doi:10.1016/j.matchemphys.2018.11.060

53. Ren $\mathrm{Y}$, Geng R, Lu Q, et al. Involvement of tgf- $\beta$ and ros in $\mathrm{g} 1$ cell cycle arrest induced by titanium dioxide nanoparticles under uva irradiation in a $3 \mathrm{~d}$ spheroid model. Int $J$ Nanomedicine. 2020;15:1997-2010. doi:10.2147/IJN.S238145
54. Li Z, Liu Z, Sun H, Gao C. Superstructured assembly of nanocarbons: fullerenes, nanotubes, and graphene. Chem Rev. 2015;115(15):7046-7117.

55. Nafisi S, Schäfer-Korting M, Maibach HI. Perspectives on percutaneous penetration: silica nanoparticles. Nanotoxicology. 2015;9 (5):643-657. doi:10.3109/17435390.2014.958115

56. Huang Y, Yu F, Park Y-S, et al. Co-administration of protein drugs with gold nanoparticles to enable percutaneous delivery. Biomaterials. 2010;31(34):9086-9091. doi:10.1016/j. biomaterials.2010.08.046

57. Kuche K, Maheshwari R, Tambe V, et al. Carbon nanotubes (CNTs) based advanced dermal therapeutics: current trends and future potential. Nanoscale. 2018;10(19):8911-8937. doi:10.1039/C8NR01383G

58. Bernardi DS, Pereira TA, Maciel NR, et al. Formation and stability of oil-in-water nanoemulsions containing rice bran oil: in vitro and in vivo assessments. J Nanobiotechnology. 2011;9 (1):1-9. doi:10.1186/1477-3155-9-44

59. Khameneh B, Halimi V, Jaafari MR, Golmohammadzadeh S. Safranal-loaded solid lipid nanoparticles: evaluation of sunscreen and moisturizing potential for topical applications. Iran J Basic Med Sci. 2015;18(1):58-63.

60. Noor NM, Khan AA, Hasham R, et al. Empty nano and microstructured lipid carriers of virgin coconut oil for skin moisturisation. IET Nanobiotechnol. 2016;10(4):195-199. doi:10.1049/ietnbt. 2015.0041

61. Chen M, Gupta V, Anselmo AC, Muraski JA, Mitragotri S. Topical delivery of hyaluronic acid into skin using SPACE-peptide carriers. J Control Release. 2014;173(1):67-74. doi:10.1016/ j.jconrel.2013.10.007

62. Ming K, Chen XG, Kweon DK, Park HJ. Investigations on skin permeation of hyaluronic acid based nanoemulsion as transdermal carrier. Carbohydr Polym. 2011;86(2):837-843. doi:10.1016/j. carbpol.2011.05.027

63. Uche LE, Gooris GS, Beddoes CM, Bouwstra JA. New insight into phase behavior and permeability of skin lipid models based on sphingosine and phytosphingosine ceramides. Biochim Biophys Acta Biomembr. 2019;1861(7):1317-1328. doi:10.1016/ j.bbamem.2019.04.005

64. Yilmaz E, Borchert H-H. Design of a phytosphingosine-containing, positively-charged nanoemulsion as a colloidal carrier system for dermal application of ceramides. Eur J Pharm Biopharm. 2005;60(1):91-98. doi:10.1016/j.ejpb.2004.11.009

65. Guillaume D, Charrouf Z. Argan oil and other argan products: use in dermocosmetology. Eur J Lipid Sci Technol. 2011;113(4):403408. doi:10.1002/ejlt.201000417

66. Lilitchan S, Tangprawat C, Aryusuk K, Krisnangkura S, Chokmoh S, Krisnangkura K. Partial extraction method for the rapid analysis of total lipids and $\gamma$-oryzanol contents in rice bran. Food Chem. 2008;106(2):752-759. doi:10.1016/j. foodchem.2007.06.052

67. Tichota DM, Silva AC, Sousa Lobo JM, Amaral MH. Design, characterization, and clinical evaluation of argan oil nanostructured lipid carriers to improve skin hydration. Int $J$ Nanomedicine. 2014;9(1):3855-3864. doi:10.2147/IJN.S64008

68. Schmaus G, Vielhaber G, Jacobs K, Franke H. 4-(1-Phenylethyl) 1,3-benzenediol: a new highly potent lightening agent. J Cosmet Sci. 2006;57(2):197-198.

69. Kim BS, Na YG, Choi JH, et al. The improvement of skin whitening of phenylethyl resorcinol by nanostructured lipid carriers. Nanomaterials. 2017;7(9):1-17. doi:10.3390/nano7090241

70. Marto J, Sangalli C, Capra P, et al. Development and characterization of new and scalable topical formulations containing N-acetyl-d-glucosamine-loaded solid lipid nanoparticles. Drug Dev Ind Pharm. 2017;43(11):1792-1800. doi:10.1080/ 03639045.2017.1339083 
71. Huh SY, Shin JW, Na JI, Huh CH, Youn SW, Park KC. Efficacy and safety of liposome-encapsulated 4-n-butylresorcinol $0.1 \%$ cream for the treatment of melasma: a randomized controlled split-face trial. J Dermatol. 2010;37(4):311-315. doi:10.1111/ j.1346-8138.2010.00787.x

72. Kwon SH, Yang JH, Shin JW, Park KC, Huh CH, Na JI. Efficacy of liposome-encapsulated 4-n-butylresorcinol and resveratrol cream in the treatment of melasma. $J$ Cosmet Dermatol. 2020;19(4):891-895. doi:10.1111/jocd.13080

73. Li JC, Zhu N, Zhu JX, et al. Self-assembled cubic liquid crystalline nanoparticles for transdermal delivery of paeonol. Med Sci Monit. 2015;21:3298-3310. doi:10.12659/MSM.894484

74. Abla MJ, Banga AK. Formulation of tocopherol nanocarriers and in vitro delivery into human skin. Int J Cosmet Sci. 2014;36 (3):239-246. doi:10.1111/ics.12119

75. Wang H, Liu M, Du S. Optimization of madecassoside liposomes using response surface methodology and evaluation of its stability. Int $J$ Pharm. 2014;473(1-2):280-285. doi:10.1016/j. ijpharm.2014.07.010

76. Li M, Zahi MR, Yuan Q, Tian F, Liang H. Preparation and stability of astaxanthin solid lipid nanoparticles based on stearic acid. Eur J Lipid Sci Technol. 2016;118(4):592-602. doi:10.1002/ ejlt.201400650

77. Hong L, Zhou C-L, Chen F-P, et al. Development of a carboxymethyl chitosan functionalized nanoemulsion formulation for increasing aqueous solubility, stability and skin permeability of astaxanthin using low-energy method. J Microencapsul. 2017;34 (8):707-721. doi:10.1080/02652048.2017.1373154

78. Lens M, Medenica L, Citernesi U. Antioxidative capacity of C60 (buckminsterfullerene) and newly synthesized fulleropyrrolidine derivatives encapsulated in liposomes. Biotechnol Appl Biochem. 2008;51(3):135. doi:10.1042/BA20080007

79. Ito S, Itoga $\mathrm{K}$, Yamato $\mathrm{M}$, Akamatsu H, Okano T. The coapplication effects of fullerene and ascorbic acid on UV-B irradiated mouse skin. Toxicology. 2010;267(1-3):27-38. doi:10.1016/j.tox.2009.09.015

80. Zhou H, Shi L, Ren Y, Tan X, Liu W, Liu Z. Applications of human skin microbiota in the cutaneous disorders for ecologybased therapy. Front Cell Infect Microbiol. 2020;10(October):112.

81. O'Neill AM, Gallo RL. Host-microbiome interactions and recent progress into understanding the biology of acne vulgaris. Microbiome. 2018;6(1):1-16. doi:10.1186/s40168-018-0558-5

82. Garg T. Current nanotechnological approaches for an effective delivery of bio-active drug molecules in the treatment of acne. Artif Cells Nanomed Biotechnol. 2016;44(1):98-105. doi: 10.3109/21691401.2014.916715

83. Mukherjee S, Date A, Patravale V, Korting HC, Roeder A, Weindl G. Retinoids in the treatment of skin aging: an overview of clinical efficacy and safety. Clin Interv Aging. 2006;1(4):327348. doi:10.2147/ciia.2006.1.4.327

84. Guo C, Khengar RH, Sun M, Wang Z, Fan A, Zhao Y. Acidresponsive polymeric nanocarriers for topical adapalene delivery. Pharm Res. 2014;31(11):3051-3059. doi:10.1007/s11095-0141398-z

85. Prasad S, Mukhopadhyay A, Kubavat A, et al. Efficacy and safety of a nano-emulsion gel formulation of adapalene $0.1 \%$ and clindamycin $1 \%$ combination in acne vulgaris: a randomized, open label, active-controlled, multicentric, Phase IV clinical trial. Indian J Dermatol Venereol Leprol. 2012;78(4):459-467. doi:10.4103/0378-6323.98077

86. Nakatsuji T, Kao MC, Fang JY, et al. Antimicrobial property of lauric acid against propionibacterium acnes: its therapeutic potential for inflammatory acne vulgaris. $J$ Invest Dermatol. 2009;129 (10):2480-2488. doi:10.1038/jid.2009.93
87. Pornpattananangkul $\mathrm{D}, \mathrm{Fu} \mathrm{V}$, Thamphiwatana $\mathrm{S}$, et al. In vivo treatment of propionibacterium acnes infection with liposomal lauric acids. Adv Healthc Mater. 2013;2(10):1322-1328. doi:10.1002/adhm.201300002

88. Chaudhary H, Kohli K, Amin S, Rathee P, Kumar V. Optimization and formulation design of gels of diclofenac and curcumin for transdermal drug delivery by box-behnken statistical design. J Pharm Sci. 2011;100(2):580-593. doi:10.1002/jps.22292

89. Liu $\mathrm{CH}$, Huang HY. In vitro anti-propionibacterium activity by curcumin containing vesicle system. Chem Pharm Bull. 2013;61 (4):419-425. doi:10.1248/cpb.c12-01043

90. Sarici G, Cinar S, Armutcu F, Altinyazar C, Koca R, Tekin NS. Oxidative stress in acne vulgaris. Eur Acad Dermatol Venereol. 2010;24(7):763-767. doi:10.1111/j.1468-3083.2009.03505.x

91. Ema M, Matsuda A, Kobayashi N, Naya M, Nakanishi J. Dermal and ocular irritation and skin sensitization studies of fullerene C60 nanoparticles. Cutan Ocul Toxicol. 2013;32(2):128-134. doi:10.3109/15569527.2012.727937

92. Inui S, Aoshima H, Nishiyama A, Itami S. Improvement of acne vulgaris by topical fullerene application: unique impact on skin care. Nanomedicine. 2011;7(2):238-241. doi:10.1016/j.nano.2010.09.005

93. Jain R, De-eknamkul W. Potential targets in the discovery of new hair growth promoters for androgenic alopecia. Expert Opin Ther Targets. 2014;18(7):787-806. doi:10.1517/14728222.2014.922956

94. Finn DA, Beadles-Bohling AS, Beckley EH, et al. A new look at the 5alpha-reductase inhibitor finasteride. CNS Drug Rev. 2006;12 (1):53-76. doi:10.1111/j.1527-3458.2006.00053.x

95. Mura S, Pirot F, Manconi M, Falson F, Fadda AM. Liposomes and niosomes as potential carriers for dermal delivery of minoxidil. J Drug Target. 2007;15(2):101-108. doi:10.1080/10611860600991993

96. Balakrishnan P, Shanmugam S, Lee WS, et al. Formulation and in vitro assessment of minoxidil niosomes for enhanced skin delivery. Int $J$ Pharm. 2009;377(1-2):1-8. doi:10.1016/j. ijpharm.2009.04.020

97. Padois K, Cantiéni C, Bertholle V, Bardel C, Pirot F, Falson F. Solid lipid nanoparticles suspension versus commercial solutions for dermal delivery of minoxidil. Int J Pharm. 2011;416(1):300304. doi:10.1016/j.ijpharm.2011.06.014

98. Giokas DL, Salvador A, Chisvert A. UV filters: from sunscreens to human body and the environment. Trends Analyt Chem. 2007;26(5):360-374. doi:10.1016/j.trac.2007.02.012

99. Golmohammadzadeh S, Jaafarixx MR, Khalili N. Evaluation of liposomal and conventional formulations of octyl methoxycinnamate on human percutaneous absorption using the stripping method. J Cosmet Sci. 2008;59(5):385-398.

100. Ambrogi V, Latterini L, Marmottini F, Pagano C, Ricci M. Mesoporous silicate MCM-41 as a particulate carrier for octyl methoxycinnamate: sunscreen release and photostability. $J$ Pharm Sci. 2013;102(5):1468-1475. doi:10.1002/jps.23478

101. Jiménez MM, Pelletier J, Bobin MF, Martini MC. Influence of encapsulation on the in vitro percutaneous absorption of octyl methoxycinnamate. Int $J$ Pharm. 2004;272(1-2):45-55. doi:10.1016/j.ijpharm.2003.11.029

102. Songkro S, Lo NL, Tanmanee N, Maneenuan D, Boonme P. In vitro release, skin permeation and retention of benzophenone-3 from microemulsions (O/W and W/O). J Drug Deliv Sci Technol. 2014;24(6):703-711. doi:10.1016/S1773-2247(14)50140-2

103. Guterres SS, Alves MP, Pohlmann AR. Polymeric nanoparticles, nanospheres and nanocapsules, for cutaneous applications. Drug Target Insights. 2007;2:117739280700200. doi:10.1177/ 117739280700200002

104. Song C, Liu S. A new healthy sunscreen system for human: solid lipid nanoparticles as carrier for 3,4,5-trimethoxybenzoylchitin and the improvement by adding vitamin E. Int J Biol Macromol. 2005;36(12):116-119. doi:10.1016/j.ijbiomac.2005.05.003 
105. Lacatusu I, Badea N, Murariu A, Bojin D, Meghea A. Effect of UV sunscreens loaded in solid lipid nanoparticles: a combinated SPF assay and photostability. Mol Cryst Liq Cryst. 2010;523(October2014):247/ [819]-259/[831]. doi:10.1080/15421401003719928

106. Fathi-Azarbayjani A, Qun L, Chan YW, Chan SY. Novel vitamin and gold-loaded nanofiber facial mask for topical delivery. AAPS PharmSciTech. 2010;11(3):1164-1170. doi:10.1208/s12249-0109475-z

107. Kato S, Taira H, Aoshima H, Saitoh Y, Miwa N. Clinical evaluation of fullerene-C 60 dissolved in squalane for anti-wrinkle cosmetics. J Nanosci Nanotechnol. 2010;10(10):6769-6774. doi:10.1166/jnn.2010.3053

108. Rabiei M, Kashanian S, Samavati SS, Jamasb S, McInnes SJP. Nanomaterial and advanced technologies in transdermal drug delivery. J Drug Target. 2020;28(4):356-367. doi:10.1080/ 1061186X.2019.1693579

109. Wang WP, Hu J, Sui H, Zhao YS, Feng J, Liu C. Glabridin nanosuspension for enhanced skin penetration: formulation optimization, in vitro and in vivo evaluation. Pharmazie. 2016;71 (5):252-257.

110. Rigon RB, Fachinetti N, Severino P, Santana MHA, Chorilli M. Skin delivery and in vitro biological evaluation of trans-resveratrol-loaded solid lipid nanoparticles for skin disorder therapies. Molecules. 2016;21(1):1-14. doi:10.3390/molecules21010116

111. Pakpayat N, Nielloud F, Fortuné R, et al. Formulation of ascorbic acid microemulsions with alkyl polyglycosides. Eur J Pharm Biopharm. 2009;72(2):444-452. doi:10.1016/j.ejpb.2009.01.005

112. Tsai YH, Lee KF, Bin HY, Wu PC, Wu P-C. In vitro permeation and in vivo whitening effect of topical hesperetin microemulsion delivery system. Int $J$ Pharm. 2010;388(1-2):257-262. doi:10.1016/j.ijpharm.2009.12.051

113. Cheng Z, Lin H, Wang Z, et al. Preparation and characterization of dissolving hyaluronic acid composite microneedles loaded micelles for delivery of curcumin. Drug Deliv Transl Res. 2020;10(5):1520-1530. doi:10.1007/s13346-020-00735-2

114. Baccarin T, Lemos-Senna E. Potential application of nanoemulsions for skin delivery of pomegranate peel polyphenols. AAPS PharmSciTech. 2017;18(8):3307-3314. doi:10.1208/s12249-0170818-x

115. Mitri K, Shegokar R, Gohla S, Anselmi C, Müller RH. Lipid nanocarriers for dermal delivery of lutein: preparation, characterization, stability and performance. Int J Pharm. 2011;414(12):267-275. doi:10.1016/j.ijpharm.2011.05.008

116. Guo CY, Yang CF, Li QL, et al. Development of a quercetinloaded nanostructured lipid carrier formulation for topical delivery. Int $J$ Pharm. 2012;430(1-2):292-298. doi:10.1016/j. ijpharm.2012.03.042

117. Berlier G, Gastaldi L, Ugazio E, Miletto I, Iliade P, Sapino S. Stabilization of quercetin flavonoid in MCM-41 mesoporous silica: positive effect of surface functionalization. $J$ Colloid Interface Sci. 2013;393(1):109-118. doi:10.1016/j. jcis.2012.10.073
118. Sapino S, Ugazio E, Gastaldi L, et al. Mesoporous silica as topical nanocarriers for quercetin: characterization and in vitro studies. Eur J Pharm Biopharm. 2015;89(December):116-125. doi:10.1016/j.ejpb.2014.11.022

119. Berlier G, Gastaldi L, Sapino S, et al. MCM-41 as a useful vector for rutin topical formulations: synthesis, characterization and testing. Int $J$ Pharm. 2013;457(1):177-186. doi:10.1016/j. ijpharm.2013.09.018

120. Pereira F, Baptista R, Ladeiras D, et al. Production and characterization of nanoparticles containing methanol extracts of Portuguese lavenders. Measurement. 2015;74:170-177. doi:10.1016/j.measurement.2015.07.029

121. Niculae G, Lacatusu I, Badea N, Stan R, Vasile BS, Meghea A. Rice bran and raspberry seed oil-based nanocarriers with selfantioxidative properties as safe photoprotective formulations. Photochem Photobiol Sci. 2014;13(4):703-716. doi:10.1039/ c3pp50290b

122. Viyoch J, Pisutthanan N, Faikreua A, Nupangta K, Wangtorpol K, Ngokkuen J. Evaluation of in vitro antimicrobial activity of Tha basil oils and their micro-emulsion formulas against propionibacterium acnes. Int J Cosmet Sci. 2006;28(2):125-133. doi:10.1111/ j.1467-2494.2006.00308.x

123. Pan-In P, Wongsomboon A, Kokpol C, Chaichanawongsaroj N, Wanichwecharungruang $\mathrm{S}$. Depositing $\alpha$-mangostin nanoparticles to sebaceous gland area for acne treatment. J Pharmacol Sci. 2015;129(4):226-232. doi:10.1016/j.jphs.2015.11.005

124. Hwang SL, Kim JC. In vivo hair growth promotion effects of cosmetic preparations containing hinokitiol-loaded poly( $\varepsilon$-caprolacton) nanocapsules. J Microencapsul. 2008;25(5):351-356. doi:10.1080/02652040802000557

125. Cho SM, Lee HY, Kim JC. Characterization and in-vitro permeation study of stearic acid nanoparticles containing hinokitiol. $J$ Am Oil Chem Soc. 2007;84(9):859-863. doi:10.1007/s11746-0071110-0

126. Golmohammadzadeh S, Imani F, Hosseinzadeh H, Jaafari MR. Preparation, characterization and evaluation of sun protective and moisturizing effects of nanoliposomes containing safranal. Iran $J$ Basic Med Sci. 2011;14(6):521-533.

127. Friedrich RB, Kann B, Coradini K, Offerhaus HL, Beck RCR, Windbergs M. Skin penetration behavior of lipid-core nanocapsules for simultaneous delivery of resveratrol and curcumin. Eur $J$ Pharm Sci. 2015;78:204-213. doi:10.1016/j.ejps.2015.07.018

128. Butnariu MV, Giuchici CV. The use of some nanoemulsions based on aqueous propolis and lycopene extract in the skin's protective mechanisms against UVA radiation. $J$ Nanobiotechnology. 2011;9(1):1-9. doi:10.1186/1477-3155-9-3

129. Tavano L, Muzzalupo R, Picci N, De Cindio B. Co-encapsulation of lipophilic antioxidants into niosomal carriers: percutaneous permeation studies for cosmeceutical applications. Colloids Surfaces $B$ Biointerfaces. 2014;114:144-149. doi:10.1016/j. colsurfb.2013.09.055
Clinical, Cosmetic and Investigational Dermatology is an international, peer-reviewed, open access, online journal that focuses on the latest clinical and experimental research in all aspects of skin disease and cosmetic interventions. This journal is indexed on CAS.
The manuscript management system is completely online and includes a very quick and fair peer-review system, which is all easy to use. Visit http://www.dovepress.com/testimonials.php to read real quotes from published authors. 